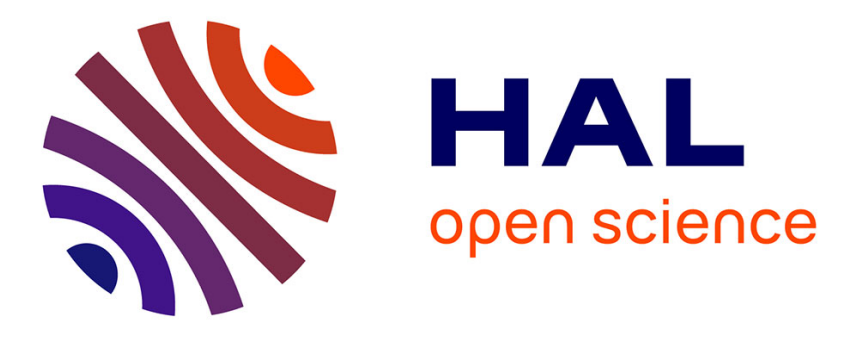

\title{
Seasonal evolution of boundary-layer turbulence measured by aircraft during the AMMA 2006 Special Observation Period
}

Frédérique Saïd, Guylaine Canut, Philippe Durand, Fabienne Lohou, Marie Lothon

\section{To cite this version:}

Frédérique Saïd, Guylaine Canut, Philippe Durand, Fabienne Lohou, Marie Lothon. Seasonal evolution of boundary-layer turbulence measured by aircraft during the AMMA 2006 Special Observation Period. Quarterly Journal of the Royal Meteorological Society, 2010, 136 (S1), pp.47-65. 10.1002/qj.475 . hal-00995991

\section{HAL Id: hal-00995991 \\ https://hal.science/hal-00995991}

Submitted on 10 Sep 2021

HAL is a multi-disciplinary open access archive for the deposit and dissemination of scientific research documents, whether they are published or not. The documents may come from teaching and research institutions in France or abroad, or from public or private research centers.
L'archive ouverte pluridisciplinaire HAL, est destinée au dépôt et à la diffusion de documents scientifiques de niveau recherche, publiés ou non, émanant des établissements d'enseignement et de recherche français ou étrangers, des laboratoires publics ou privés. 


\title{
Seasonal evolution of boundary-layer turbulence measured by aircraft during the AMMA 2006 Special Observation Period
}

\author{
F. Saï,* G. Canut, P. Durand, F. Lohou and M. Lothon \\ Université de Toulouse/CNRS 5560, Laboratoire d'Aérologie, Toulouse, France
}

\begin{abstract}
During the African Monsoon Multidisciplinary Analysis (AMMA) field campaign, the ATR research aircraft made observations of fluxes and thermodynamics during three 15-day periods, which allowed the seasonal evolution of the atmospheric boundary-layer (ABL) characteristics to be monitored before and after the monsoon onset. As expected, temperature and humidity showed a contrast between dry warm conditions and moister cooler conditions from one period to the other. Most of the time, the wind blew from the west (northwesterly to southwesterly) in the ABL and from the east in the free troposphere. Following rainfall events occuring in July and August, surface sensible heat flux decreased and evaporation increased while the momentum flux remained large in the entire boundary layer, whatever the period. The aim of this paper is to characterize turbulence in terms of fluxes and length-scales for ABLs that exhibit particular characteristics relative to (i) entrainment at the top, (ii) wind rotation at the interface between the monsoon and the Saharan air layer and (iii) seasonal variability. In spite of the poorer accuracy of the turbulent flux estimations at the top of the ABL, the flux profiles were observed to increase or decrease linearly with altitude which enabled accurate estimates of entrainment flux ratios. It was found that the moisture flux distribution in the ABL was governed by top-down processes during the driest period and a mixture of top-down and bottom-up processes during the monsoon period. Significant differences in turbulence length-scales were also highlighted.
\end{abstract}

KEY WORDS entrainment; monsoon; Harmattan; atmospheric turbulent fluxes

\section{Introduction}

The climate in tropical areas of West Africa is characterized by two distinct seasons, linked to the northward migration of the Intertropical Convergence Zone (ITCZ) with the seasonal motion of the sun. South of the Sahara desert, there is a dry season in winter with dry and warm easterly to northerly winds (Harmattan) associated with high pressure over the Sahara, whereas during summer the monsoon winds blow from the southwest in the lower layers, carrying cooler and moister air associated with rainfall. The migration of the ITCZ induces a meridional variability in rainfall. The Sahel zone, where this study took place, is therefore usually defined in terms of annual rainfall ranging from 200 to $500 \mathrm{~mm}$ (Figure 1; Monteith, 1991). This area extends from $13^{\circ}$ to $17^{\circ} \mathrm{N}$. During 2006, the water vapour mixing ratio rarely reached $5 \mathrm{~g} \mathrm{~kg}^{-1}$ below $5 \mathrm{~km}$ height in winter, whereas it could reach $20 \mathrm{~g} \mathrm{~kg}^{-1}$ during summer in the lower layers, decreasing to about $5 \mathrm{~g} \mathrm{~kg}^{-1}$ at $4 \mathrm{~km}$ above ground level (agl), as reported by Lothon et al. (2008).

Both rainfall and thermodynamic conditions of the air mass have drastic effects on the energy balance

\footnotetext{
${ }^{*}$ Correspondence to: F. Saïd, Centre de Recherches Atmosphériques, 8 route de Lannemezan, 65300 Campistrous, France.

E-mail: frederique.said@aero.obs-mip.fr
}

at the surface, as pointed out by the observations of the HAPEX-Sahel 1992 experiment during the August-October Intensive Observation Period (IOP) of the campaign (Goutorbe et al., 1994). Wai et al. (1997) focused on the variability of the boundary layer during the HAPEX-Sahel wet-dry season transition. They identified a 'dramatic shift in surface conditions in response to the large-scale transition from wet to dry seasons'. The evaporative fraction, defined as

$$
E F=\frac{L E_{0}}{H_{0}+L E_{0}},
$$

where $L E_{0}$ and $H_{0}$ are the latent heat and sensible heat fluxes at the ground respectively, is a good indicator to quantify this change. $E F$ varied from 0.8 to 0.4 during HAPEX-Sahel, following the progressive decrease of moisture from the rainy to the dry season (Gash et al., 1997; Saïd et al., 1997). Fourteen years after HAPEXSahel, the African Monsoon Multidisciplinary Analysis (AMMA) field campaign (Redelsperger et al., 2006) gave an opportunity for additional extensive studies in West Africa.

A large proportion of the AMMA intensive observations were performed in the Niamey area of Niger $\left(13^{\circ} 29^{\prime} \mathrm{N}, 2^{\circ} 10^{\prime} \mathrm{N}, 205 \mathrm{~m}\right.$ above sea level, asl; Figure 1) and spanned the period from June to August i.e. a period 


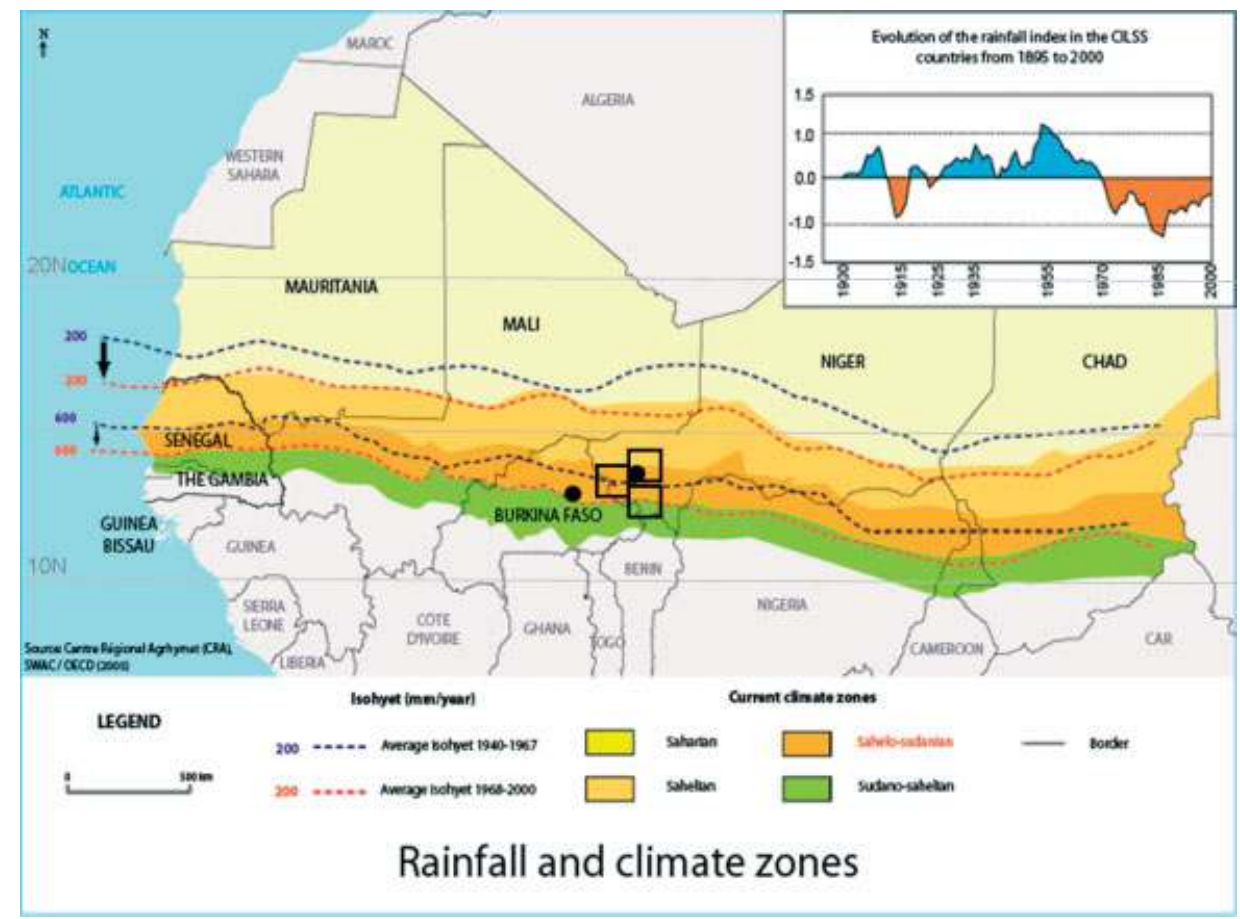

Figure 1. Rainfall and climatic zones as provided by ECOWAS-SWAC/OECD 2006 (http:www.atlas-ouestafrique.org/spip.php?article29). The Sahelian zone is defined and the shift in the isohyets linked to the climatic change at the end of the last century. The black boxes show the areas overflown by the SAFIRE ATR42. The black dots indicate Ouagadougou in Burkina Faso and Niamey in Niger.

of increasingly moist conditions leading to the wet mature monsoon conditions. This choice was made with the intention of investigating the period preceding and following the monsoon onset, which corresponds to a few days of suppressed conditions over West Africa linked to the meridional shift of the ITCZ. According to a statistical analysis over the period 1968-1990 (Sultan and Janicot, 2003), the onset period lasts two weeks and is centred on 24 June \pm 8 days. Before the onset, deep convection occurs south of $10^{\circ} \mathrm{N}$, whereas it is observed north of $13^{\circ} \mathrm{N}$ after the onset. This allows the advection of moisture from the Gulf of Guinea by the low-level monsoon. In 2006, the onset was delayed by 10 days and was centred on 3 July (as estimated by Janicot et al., 2008), extending from 25 June to 10 July. So the three aircraft observation periods described in the present work happened to take place before, during and after the onset period. The three Special Observation Periods (SOPs) are respectively called SOP1, SOP2a1 and SOP2a2 hereafter.

Five research aircraft, based at Niamey or Ouagadougou (Burkina Faso) airports (Figure 1), documented the atmosphere from June to September (Lebel et al., 2009). One objective of the flights performed during SOP1 and SOP2a1 was to study the Saharan heat low and the InterTropical Discontinuity (ITD) with two aircraft (DLR Falcon 20 and SAFIRE Falcon 20) flying in the mid-troposphere. They were equipped with a wind Doppler lidar and a water vapour lidar respectively (Messager et al., 2009; Flamant et al., 2009). The SAFIRE Falcon 20 also launched dropsondes. Meanwhile, the SAFIRE ATR42 documented the boundary layer and the low troposphere in the vicinity of Niamey, by collecting dynamic, thermodynamic, radiative and aerosol measurements. The aim was to study the role of turbulence at the interface between the monsoon and the Harmattan and also to survey the mineral dust composition of the low layers and to quantify the impact of squall lines at the beginning of the monsoon season. During SOP2a2, studies focused on the sampling of mesoscale convective systems (MCS). They involved the five aircraft (Lebel et al., 2009). The FAAM (Facility for Airborne Atmospheric Measurements) BAE 146 and SAFIRE ATR42 aircraft measured dynamics, chemistry and aerosols in the low layers and mid-troposphere before and after the MCS events (Crumeyrolle et al., 2008). Both Falcons documented the dynamics and chemistry in the midtroposphere during the MCS activity while the European M55 Geophysica explored the upper layers. Additional flights from the BAE 146, Falcon and M55 Geophysica targeted the response of the dynamics to the land surface state (Taylor et al., 2007; Stewart et al., 2008), the downstream conditions of the mesoscale convective systems and the long-range transport (Ancellet et al., 2009).

The purpose of this paper is to describe the atmospheric boundary layers (ABLs) observed during the 35 flights of the ATR42 between June and August. The main characteristics will be analysed in the framework of the seasonal evolution due to the arrival of the monsoon over the experimental area. The boundary-layer development will be described through the profiles of the wind and thermodynamic parameters, and the level of the ABL top relative to the shearing layer separating the monsoon flow from the Harmattan flow. The turbulence structure will 
be described through fluxes at the surface, their profile in the ABL, and the characteristic scales. The respective roles of the entrainment at the top of the ABL and of the evaporation at the surface on the moisture flux profile will be highlighted. Aircraft measurements and flights are presented in sections 2 and 3. Section 4 is devoted to the description of the boundary-layer depth and monsoon depth retrieval method and section 5 to the estimation of flux error. Results are presented next, considering successively the mean conditions (section 6), the turbulent fluxes (section 7), the length-scales (section 8) and, finally, the correlation coefficients (section 9).

\section{Instrumentation and data processing}

The French ATR42 aircraft is equipped to measure the wind and thermodynamic parameters along its trajectory. Although AMMA was the first scientific campaign during which the plane was operated, the measurement systems and data processing were quite similar to those used on the previous aircraft (e.g. Lambert and Durand, 1998; Durand et al., 1998; Saïd et al., 2005). According to their response time, the signals delivered by the various sensors were generally recorded at a rate ranging from 1 to $50 \mathrm{~s}^{-1}$.

The wind was computed from the vectorial sum of the groundspeed and the airspeed of the aircraft. The former was provided by the inertial navigation unit, which was the same as in the former French planes (Sagem Uliss 45). The latter was computed according to Lenschow (1986) from the measurements of the sideslip and attack angles, and the true airspeed magnitude (TAS). The sideslip and attack angles were computed from pressure differences measured between the vertically aligned and horizontally aligned pressure ports, respectively, on the nose radome (with Rosemount 1221 pressure transducers), according to the technique first described by Brown et al. (1983). TAS was measured with a fast Pitot tube (with a Rosemount 1221 pressure transducer). All the parameters were calibrated and corrected for the plane dynamic effects using numerical simulations and flight manoeuvres performed before the campaign.

Air temperature was retrieved from a platinum wire thermometer placed in a Rosemount housing (E102AL Rosemount), after correction for the adiabatic heating due to the airspeed of the plane. Moisture fluctuations were measured by a Lyman-alpha sensor (AIR model), installed close to the nose of the aircraft. The signal was calibrated against the true water vapour density computed from the air temperature, pressure and dewpoint temperature. The latter was measured by a chilledmirror sensor (General Eastern 1011).

The three wind components, the temperature and the moisture were processed at a common rate of $25 \mathrm{~s}^{-1}$ for turbulence statistics computation. Given the TAS at which the plane flies in the lower layers, this rate allowed the turbulence to be captured on length-scales down to around $4 \mathrm{~m}$, which, above the atmospheric surface layer, is well within the inertial subrange of the turbulent field.
Turbulence moments were computed on straight level flight runs $40 \pm 5 \mathrm{~km}$ long in order always to sample a comparable number of large eddies. The various quantities (i.e. variances, covariances, etc.) were computed twice, firstly on the detrended time series and, secondly, on the high-pass-filtered time series, with a cut-off wavelength of about $5 \mathrm{~km}$. The use of these two values to extract the best estimate of the covariances will be described in detail in section 5 .

\section{Flight tracks and flight periods}

As one major aim of the flights was to study the interaction between the monsoon and the mid-troposphere, the flight strategy focused on the vertical structure of the atmosphere. Constant-level legs were flown in a vertical plane. Horizontal spatial variability was also probed since the flight legs were at least $80 \mathrm{~km}$ long. The vertical pattern (orientated south-north or west-east) was sometimes complemented by another vertical plane, perpendicular to the first, in order to obtain information about horizontal anisotropy in case organized structures occurred. When fluxes and turbulent parameters were computed, each vertical plane was split, here, into two semi-planes as indicated in Figure 2(a), which displays an example of a flight track (flight 18). Letters W, E, S and $\mathrm{N}$ refer to a west-, east-, south- or north-positioned semi-plane. Figure 2(a) is the horizontal track and Figure 2(b) the vertical track. In the latter, the water vapour mixing ratio is plotted along the track. It clearly shows the gradient in water vapour mixing ratio at the inversion level. The water vapour mixing ratio is $9.5 \mathrm{~g} \mathrm{~kg}^{-1}$ in the $\mathrm{ABL}$ (monsoon) and around $4 \mathrm{~g} \mathrm{~kg}^{-1}$ in the Saharan Air Layer (SAL) above the ABL.

The level of the different legs was set for each flight, based upon a first sounding that allowed the ABL depth, $Z_{\mathrm{i}}$, and the height of the wind rotation from the monsoon to the Harmattan, $Z_{\mathrm{s}}$, to be estimated. The track of this sounding can be seen in Figure 2(b). This preliminary sounding was mostly performed over Banizoumbou $\left(13^{\circ} 32^{\prime} \mathrm{N}, 2^{\circ} 40^{\prime} \mathrm{N}, 250 \mathrm{~m}\right.$ asl $)$, a ground site located $55 \mathrm{~km}$ east of Niamey. The climbing rate was always less than $165 \mathrm{~m} \mathrm{~min}^{-1}$, to enable sharp variations in thermodynamic parameters to be detected. Due to the small flight range of the aircraft (4 hours in the vicinity of the airport, 3.5 hours for remote flights), the number of legs in the second vertical plane was always smaller, with probing the boundary layer kept as a priority. For safety reasons, it was not possible to fly lower than $200 \mathrm{~m}$ agl. In the following, all heights are considered agl.

Another flight pattern, devoted to the description of the chemistry of the surface, consisted of a 'square' horizontal track, using parallel legs flown at $200 \mathrm{~m}$ over an area $120 \mathrm{~km} \times 120 \mathrm{~km}$.

Figure 3 depicts the distribution of the flights over the period in relationship to rainfall. Rainfall estimates were provided by the NASA-TRMM database (http://disc2.nascom.nasa.gov/Giovanni/tovas/TRMM_V6 

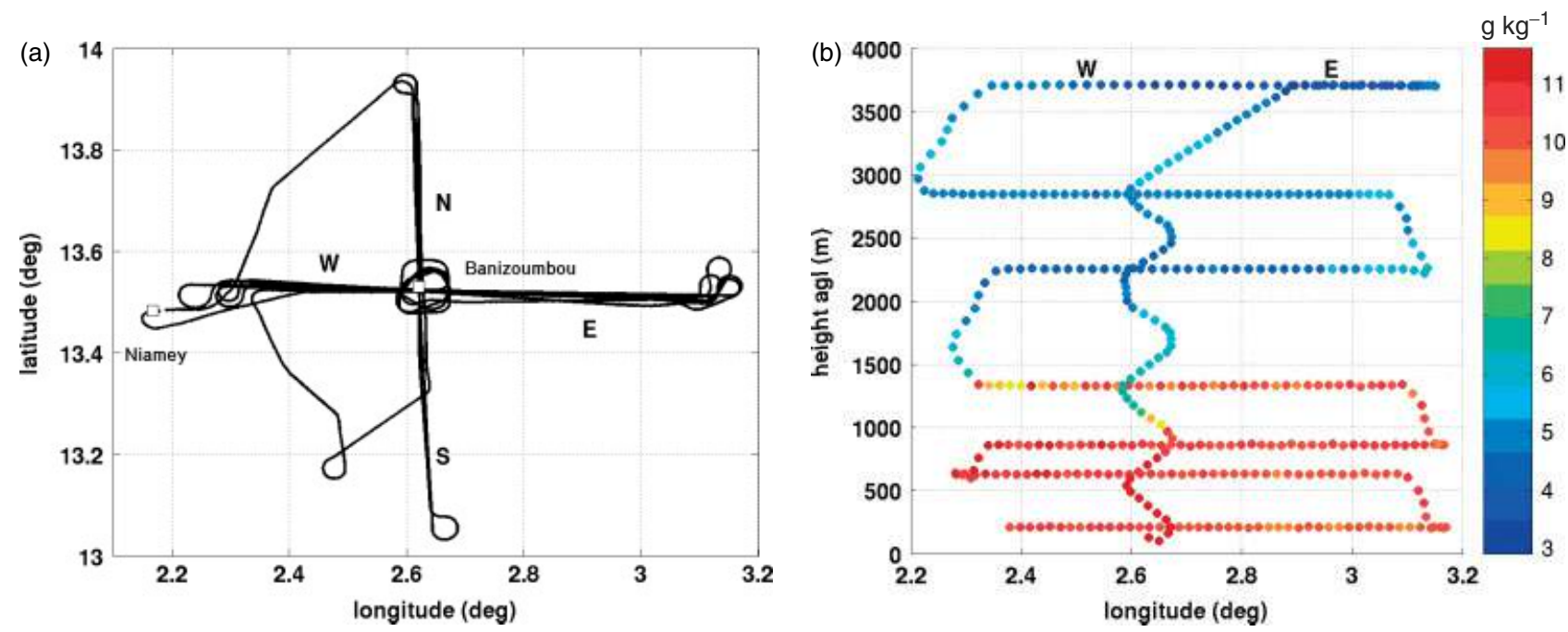

Figure 2. An example of flight pattern probing two crossed vertical planes in the low troposphere, showing (a) the ground track and (b) the humidity mixing ratio projected onto a west-east vertical plane, for the west-east level runs and an ascending sounding.

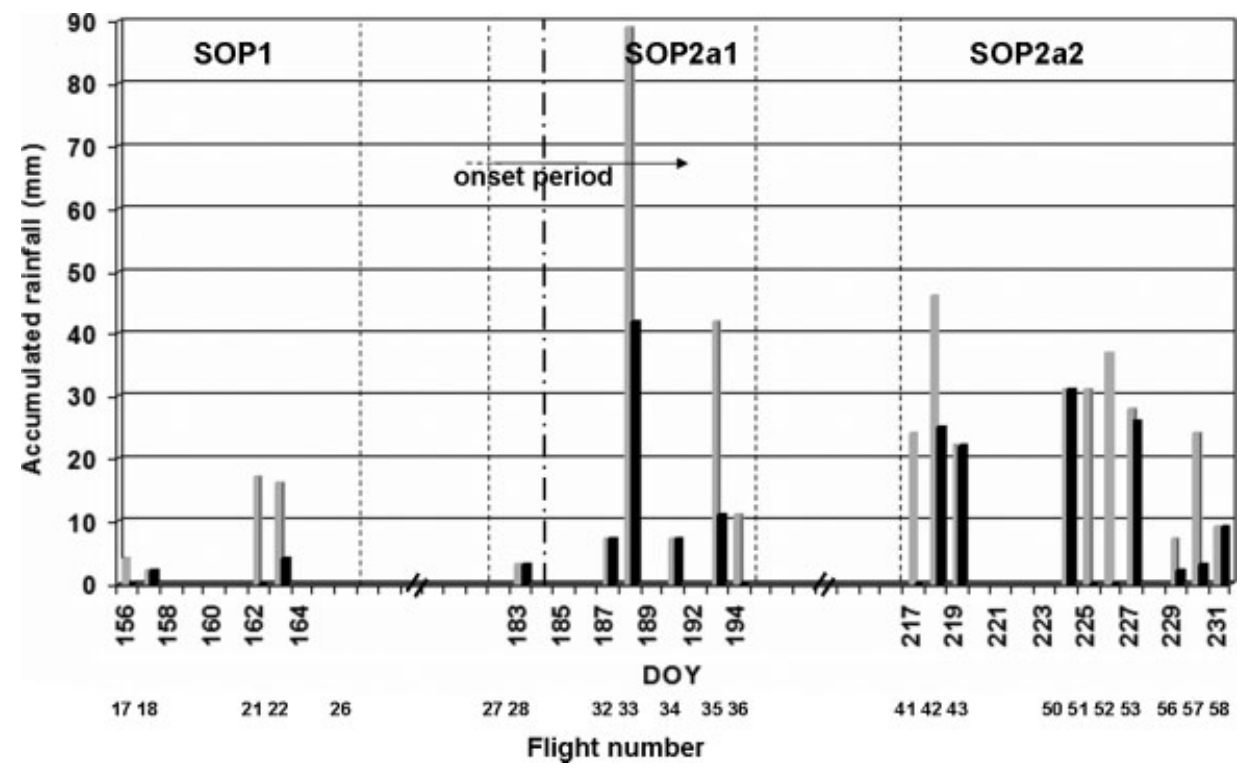

Figure 3. Accumulated rainfall (mm) along the flight track during the three days before the flight (grey) and the 24 hours before the flight (black). The SOP limits are shown by vertical dotted lines. The monsoon onset central time and duration are indicated by the dashed-dotted line and the horizontal arrow, respectively.

.3B42.2.shtml). Here we use accumulated rainfall averaged along the different flight paths during both the 3 days and the 24 hours preceding the flights. Daily accumulated rainfall along the flight paths is also shown in Table I, which lists the characteristics and mean parameters of the flights. For each rainfall estimation, the percentage of surface affected by rainfall relative to the surface overflown by the aircraft is indicated. The onset period is indicated in Figure 3; SOP1 was completed before the onset, SOP2a1 during and SOP2a2 after the onset. Rainfall events were scarce before the onset and increased after the onset period with some significant events preceding flights 33 and 35. After 1 July (flight 27), half the flights followed an important rainfall event occurring within the previous 24 hours, with more frequent rainfall during the last SOP.

\section{Estimating ABL height and monsoon depth}

There are several definitions of the ABL height. Sullivan et al. (1998) compared the flux method, where $Z_{\mathrm{i}}$ is taken as the vertical location of the average minimum heat flux, to the gradient method, where $Z_{\mathrm{i}}$ is defined as the vertical location of the maximum potential temperature gradient. They preferred the latter estimation, which provides smoother time variations and better matches with the boundary-layer interface simulated in a convection tank. In this study, we took another estimation, the top of the well-mixed layer (the layer where potential temperature and water vapour mixing ratio remain constant), or the cloud-base height. This was motivated by the fact that the location of the maximum potential temperature gradient could not easily be detected in cases of rapidly growing or cloudy ABLs. 


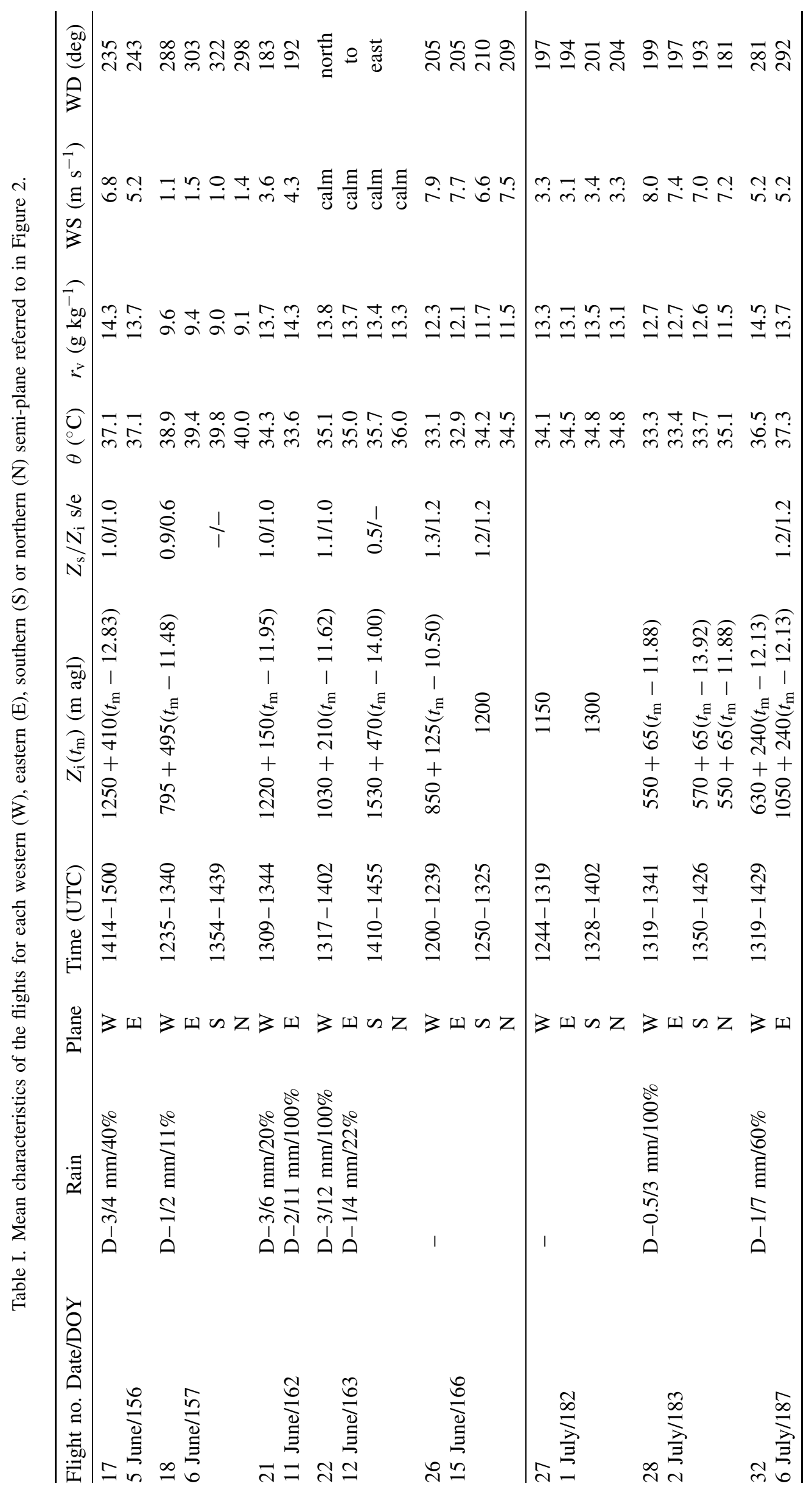




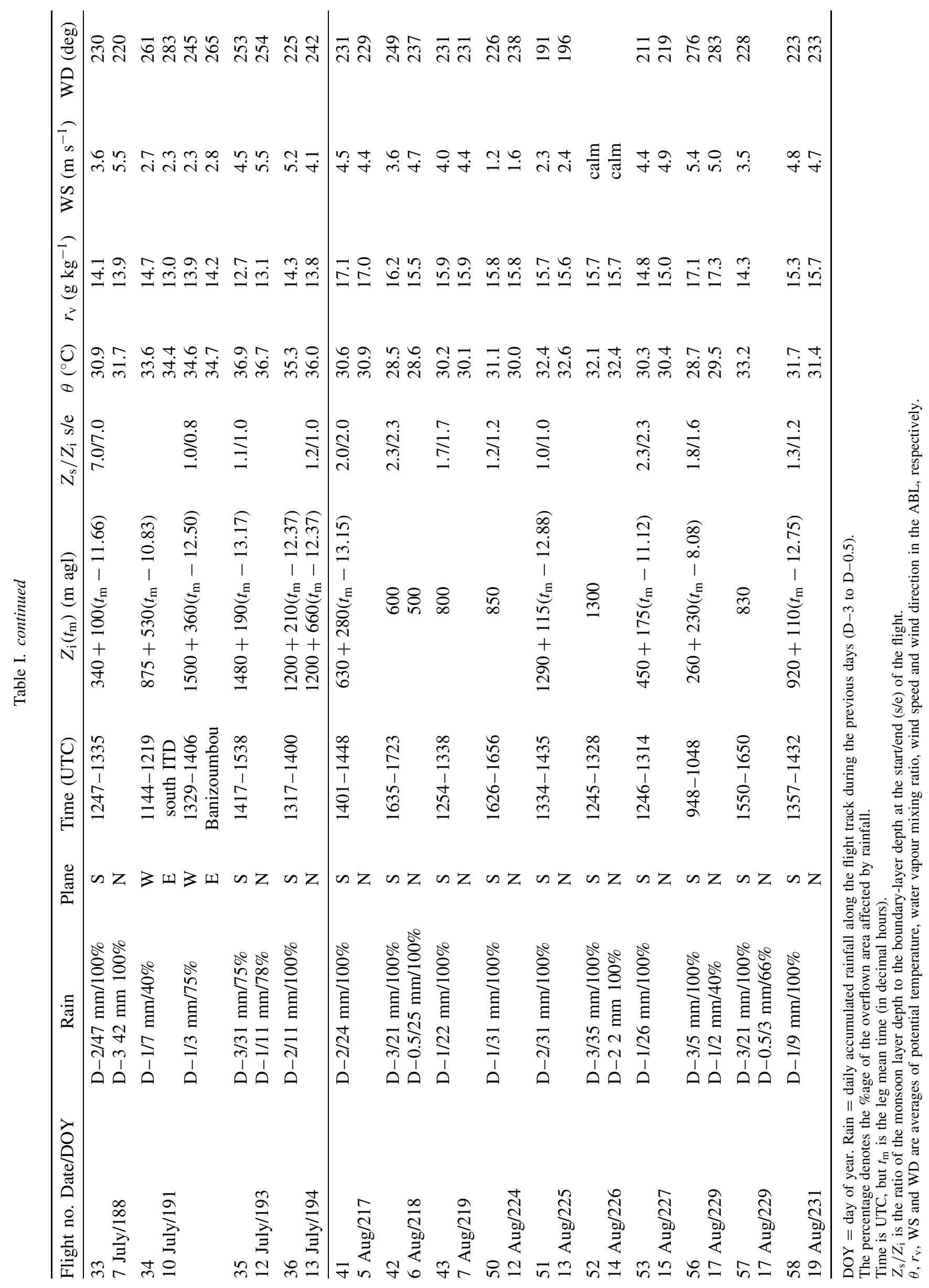


$Z_{\mathrm{i}}$ estimates and their growth rate were obtained using aircraft vertical soundings and aircraft descents during the vertical planes. When the flights were not far from Niamey, ABL growth rates were checked with the Niamey UHF wind profiler radar from which the ABL top was estimated at the level where the reflectivity was a maximum. In addition, some flight runs were performed close to the ABL top where the heat flux was significantly negative.

Two examples are illustrated in Figure 4(a) and (b) to highlight the differences in the ABL development between the SOPs considered. The first is a flight performed on 5 June (flight 17), long before the monsoon onset. Thermodynamic parameters and wind vectors measured during the sounding are shown. $Z_{\mathrm{i}}$ was determined at the shift in potential temperature and drop in humidity mixing ratio to be $1250 \mathrm{~m}$ agl (1250 UTC). Temperature and humidity show large variability in a layer extending from $Z_{\mathrm{i}}$ to $1600 \mathrm{~m}$. The wind profile indicates westerly wind (monsoon) up to $1600 \mathrm{~m}$ and easterly wind (Harmattan) above; this level is the height of wind rotation or the shear height $Z_{\mathrm{s}}$. At this time of the day, the ABL top has not yet reached the shear height. The $Z_{\mathrm{i}}$ and $Z_{\mathrm{s}}$ levels are separated by the entrainment zone.

After the vertical sounding, the aircraft descended with stacked horizontal legs. At 1355 UTC, it penetrated into the mixed-layer again, which had reached $1700 \mathrm{~m}$. From the two estimates of $Z_{i}$, about 1 hour apart, the following linear relationship was calculated for $Z_{\mathrm{i}}$ :

$$
Z_{\mathrm{i}}\left(t_{\mathrm{m}}\right)=1250+410\left(t_{\mathrm{m}}-12.83\right)
$$

and extrapolated for the following flight runs within the ABL. $t_{\mathrm{m}}$ was the mean time (in decimal hours) of the flight run. The ABL growth rate, $410 \mathrm{~m} \mathrm{~h}^{-1}$, was checked on the UHF profiler time-height cross-section of reflectivity, which indicated a growth rate of $440 \mathrm{~m} \mathrm{~h}^{-1}$ The radar wind profiles also indicated that $Z_{\mathrm{i}}$ had not yet reached $Z_{\mathrm{s}}$ at $1355 \mathrm{UTC}\left(Z_{\mathrm{s}} / Z_{\mathrm{i}}=1.1\right)$ but had reached it at the end of the flight.

Figure 4(b) gives another example of vertical exploration for a cloudy day during SOP2a2. In this case, $Z_{\mathrm{i}}=630 \mathrm{~m}$ agl (1309 UTC) at the cloud base, which was detected at the level where dew-point and static temperature were equal. Both variables indicated a deep layer of cloud extending up to $2150 \mathrm{~m}$ agl, which is even higher than the shear level $(1770 \mathrm{~m})$. Consequently, the growth rate of the $\mathrm{ABL}$ was smaller than in the previous case: $280 \mathrm{~m} \mathrm{~h}^{-1}$ instead of $410 \mathrm{~m} \mathrm{~h}^{-1}$. The UHF profiler, located $140 \mathrm{~km}$ away from the sounding area, indicated a growth rate of $150 \mathrm{~m} \mathrm{~h}^{-1}$ at the flight time.

An accurate determination of $Z_{\mathrm{i}}$ is crucial to characterize the transfers inside and outside the ABL but is always difficult to obtain. An error in $Z_{\mathrm{i}}$ can lead to an error on the fluxes interpolated at the surface and ABL top, from which entrainment estimates (for instance) may be deduced. The order of magnitude of this error is discussed in Canut et al. (2009). Information about $Z_{\mathrm{i}}$ and $Z_{\mathrm{s}} / Z_{\mathrm{i}}$ are given in Table $I$ for all flights. $Z_{\mathrm{s}} / Z_{\mathrm{i}}$ was estimated using aircraft and profiler information and is indicated at the start and end of the vertical planes explored by the aircraft.

\section{Flux error calculations. Flux correction}

Neglecting the sensor accuracy, which is not more than 5-10\% according to Hildebrand (1991) and Lloyd et al. (1997), two types of error are involved when estimating turbulent fluxes by the eddy-correlation method: the systematic error $\epsilon_{\mathrm{S}}$ which is linked to the loss due to high-pass filtering, and the random error $\epsilon_{\mathrm{r}}$ which is due to the fact that a flight leg is a finite sample of a random process.

Wyngaard (1983) suggested a parametrization of the random error:

$$
\epsilon_{\mathrm{r}}=\left\{\frac{2 l_{w s}}{L}\left(1+R_{w s}^{-2}\right)\right\}^{1 / 2},
$$

where $L$ is the sample length of the run, $l_{w s}$ the integral scale for the instantaneous covariance $w^{\prime} s^{\prime} . w$ is the vertical component of wind velocity, $s$ is a scalar and prime denotes turbulent fluctuations. $l_{w s}$ is computed from the autocorrelation function of the signal $w^{\prime} s^{\prime}$, integrated up to its first zero, as suggested by Lenschow and Stankov (1986). $R_{w s}$ is the correlation coefficient between $w$ and $s$ :

$$
R_{w s}=\frac{\overline{w^{\prime} s^{\prime}}}{\left(\overline{w^{\prime 2}} \overline{s^{\prime 2}}\right)^{1 / 2}} .
$$

Our estimates of random error are presented in Figure 5 for heat and moisture fluxes, as a function of the reduced height $Z_{*}=Z / Z_{\mathrm{i}}$ for the different SOPs. In order to compare the degree of confidence on the calculated averages and standard deviations shown in the figure, we indicate the sample size for each level bin and each SOP in Table II. The sample size is sometimes smaller for the moisture flux since this parameter could not be provided for two flights. The sample size is very large at low levels during SOP2a2, due to the numerous horizontal explorations performed during this period. It is very small (6) at the top of the ABL during SOP1, which means that the statistics will be less reliable there.

The random errors at low levels are $20 \pm 15 \%$ for the heat flux, and reach very large values close to $Z_{\mathrm{i}}$ (nearly 100\%) when the flux was close to zero. This is in agreement with values found in the literature (Mann and Lenschow, 1994; Bernard-Trottolo et al., 2003). There is only a small difference between the SOPs. The errors are larger at low levels for the moisture flux, with some variability between the SOPs. The drier the conditions, the larger the error. $\epsilon_{\mathrm{r}}$ is $25 \%$ during SOP $2 \mathrm{a} 2$ and can reach $60 \%$ during SOP1. Contrasting with the heat flux, the moisture flux random error does not always increase with height, and when it does, the increase is smaller. $\epsilon_{\mathrm{r}}$ close to $Z_{\mathrm{i}}$ is 1.5 times the low-level value during SOP2a1 and SOP2a2 whereas it is half of its low-level value during SOP1. This can be connected to the sign of 

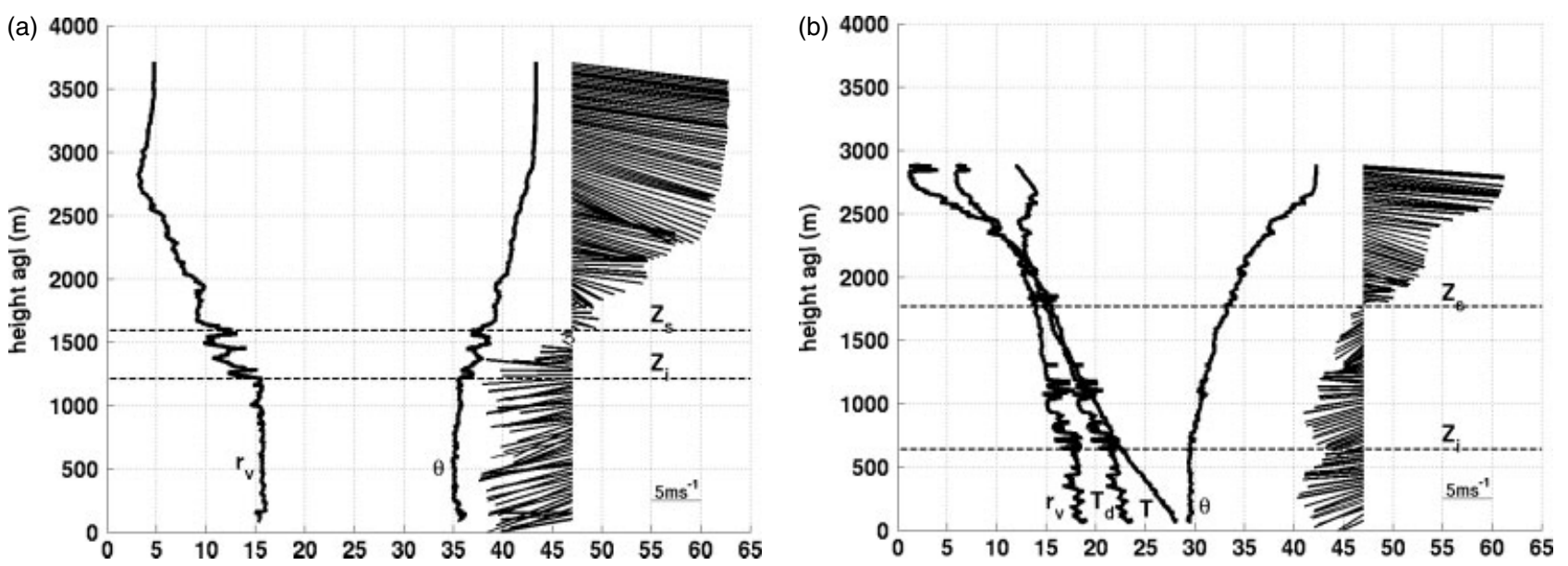

Figure 4. Examples of soundings used to estimate $Z_{\mathrm{i}}$ and $Z_{\mathrm{s}}$. Plotted parameters are potential temperature $\theta\left({ }^{\circ} \mathrm{C}\right.$ ), water vapour mixing ratio $r_{\mathrm{v}}$ $\left(\mathrm{g} \mathrm{kg}^{-1}\right)$, static temperature $T\left({ }^{\circ} \mathrm{C}\right)$, dew-point temperature $T_{\mathrm{d}}\left({ }^{\circ} \mathrm{C}\right)$ and horizontal wind, on (a) 5 June between 1238 and $1301 \mathrm{UTC}$, a clear day, and (b) 5 August between 1306 and 1324 UTC, a cloudy day.
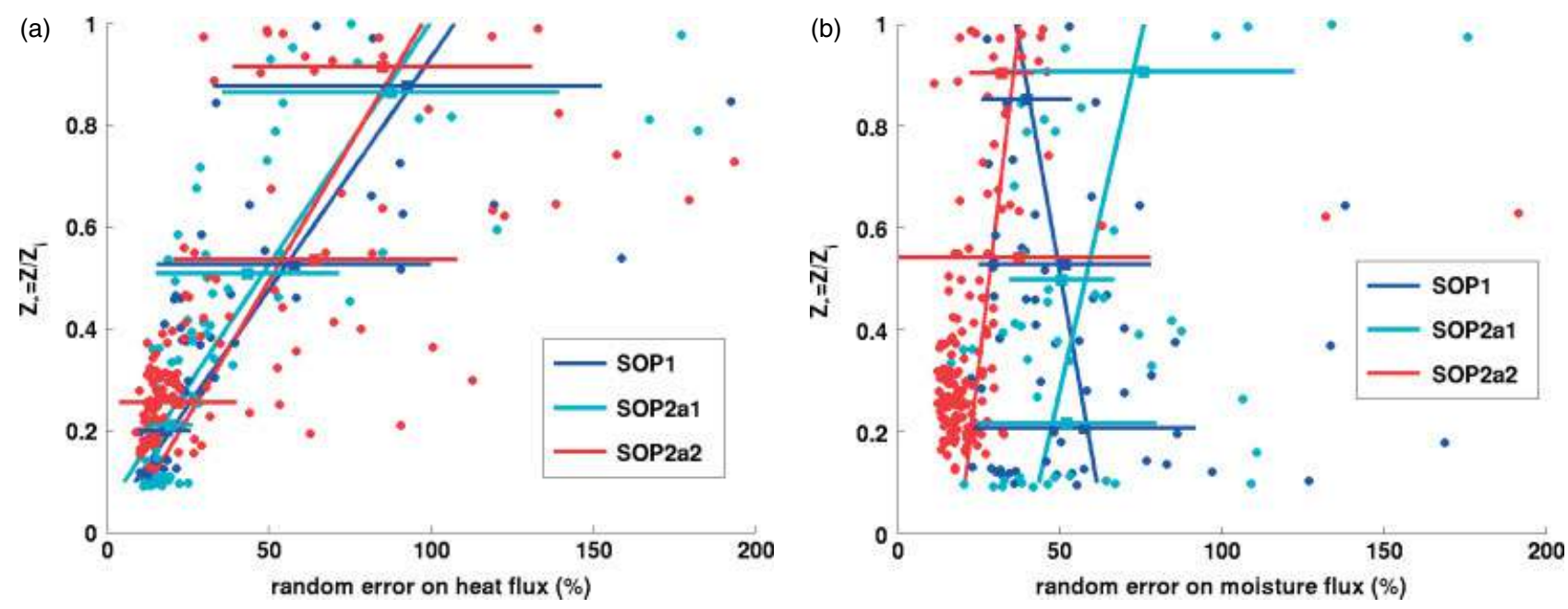

Figure 5. Vertical profiles of random errors on (a) heat and (b) moisture flux. Averages and standard deviations (horizontal bars) are plotted depending on the SOP in the three height bins defined in Table II. The oblique lines are the best linear fits.

Table II. The $M / N$ values in each box represent the number of flux estimates used in the three height ranges and during the three SOPs, for the heat or momentum flux, $M$, and for the moisture flux, $N$.

\begin{tabular}{cccc}
\hline$Z / Z_{\mathrm{i}}$ range & SOP1 & SOP2a1 & SOP2a2 \\
\hline $0.1-0.4$ & $36 / 35$ & $35 / 26$ & $102 / 102$ \\
$0.4-0.7$ & $17 / 17$ & $17 / 11$ & $24 / 24$ \\
$0.7-1.0$ & $6 / 6$ & $19 / 11$ & $21 / 21$ \\
\hline
\end{tabular}

the moisture flux divergence, which varied greatly during the campaign (section 7). $\epsilon_{\mathrm{r}}$ will be discussed in section 9.

To reduce the random error, we applied a high-pass filter to the data to remove the contribution of the largest length-scales, which were poorly resolved along the run. The consequence of this filtering was an increase in the systematic error $\epsilon_{\mathrm{s}}$ since the latter is an estimate of the flux loss due to filtering.

From observations and theoretical considerations, Mann and Lenschow (1994) established the following expression for the systematic error:

$$
\epsilon_{\mathrm{s}}=\frac{F_{\mathrm{u}}-F_{\mathrm{f}}}{F_{\mathrm{u}}}=b Z_{\mathrm{i}}\left(\frac{Z}{Z_{\mathrm{i}}}\right)^{1 / 2}\left(\frac{1}{L_{\mathrm{c}}}-\frac{1}{L}\right),
$$

where $F_{\mathrm{u}}$ and $F_{\mathrm{f}}$ are the unfiltered and filtered fluxes respectively. $L_{\mathrm{c}}$, the cut-off wavelength of the high-pass filter, is $5 \mathrm{~km}$ (section 2). $b$ is a coefficient taken as 1.2 by Mann and Lenschow (1994), Lambert and Durand (1999) and Durand and Bourcy (2001). However, Mann and Lenschow (1994) note that this value is likely to change according to the mesoscale structure in the ABL.

As we computed both the filtered and unfiltered fluxes, we were able to extract $b$ by a least-squares fit on the plot of the second member of (3) against the third (divided by $b$ ). The result is presented in Figure 6, where the individual values of the heat and moisture fluxes have been averaged in four bins. The value obtained (1.4) is not far from 1.2. Since $\left(L_{c}{ }^{-1}-L^{-1}\right)$ is almost constant, $\epsilon_{\mathrm{s}}$ is directly linked to the values of $Z$ and $Z_{\mathrm{i}}$. $\epsilon_{\mathrm{s}}$ varies between $10 \pm 20 \%$ and $30 \pm 35 \%$ here. These 


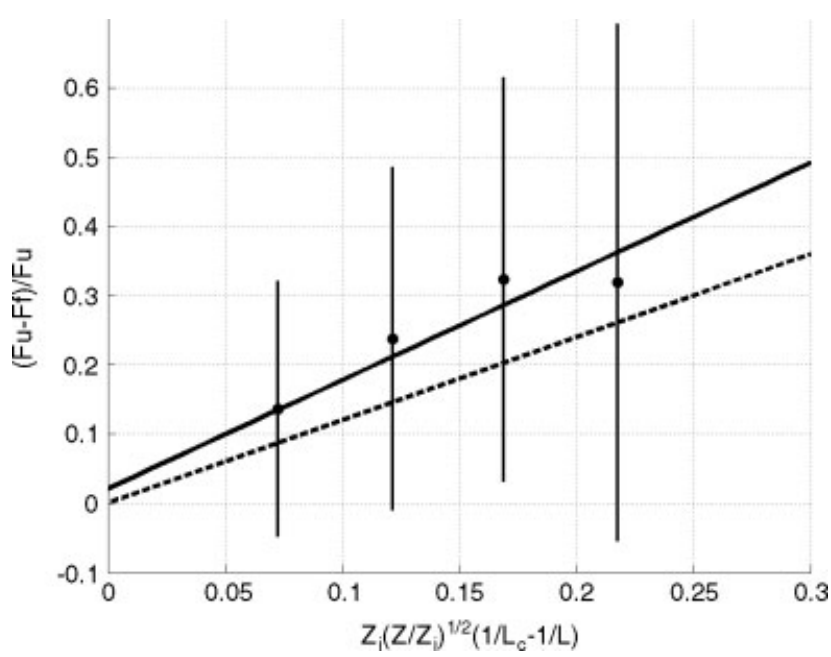

Figure 6. Systematic flux error computed from the observations against the parametrized error (divided by the $b$ coefficient; see text for explanations). The solid line is the regression line (slope 1.4) and the dotted line is the 1.2-slope line found in the literature.

are commonly obtained values (Mann and Lenschow, 1994; Bernard-Trottolo et al., 2003). It was found (not shown here) that the largest $\epsilon_{\mathrm{s}}$ corresponded to highlevel measurements and that $\epsilon_{\mathrm{s}}$ values were larger during SOP1, whatever the level, since $Z_{\mathrm{i}}$ was larger during this $\mathrm{SOP}$, as will be shown in next section.

Finally, the best flux estimate $F_{\mathrm{c}}$ is the filtered flux corrected for the systematic error according to (3):

$$
\frac{F_{\mathrm{c}}-F_{\mathrm{f}}}{F_{\mathrm{c}}}=1.4 Z_{\mathrm{i}}\left(\frac{Z}{Z_{\mathrm{i}}}\right)^{1 / 2}\left(\frac{1}{L_{\mathrm{c}}}-\frac{1}{L}\right) .
$$

This method reduces the scatter in the raw fluxes, without introducing a systematic filter error.

To conclude this section, we found expected moderate values of the errors at low levels, except for the moisture flux during the first two SOPs, when the surface was very dry. Higher values were obtained close to $Z_{\mathrm{i}}$ where the error is larger when the flux is closer to zero i.e. for heat flux during all SOPs and moisture flux during SOP2a1. So there is a marked seasonal variability in the error associated with the moisture flux. We will discuss this later.

\section{Results: Evolution of mean conditions}

Table I displays the main characteristics of the mixed layers studied. Results are shown for each western, eastern, southern and northern vertical semi-plane shown in Figure 2(a). Most of the flights were performed between 1200 and 1500 UTC, except flights 42, 50 and 57, flown between 1550 and 1720 UTC to investigate post-rainfall conditions immediately after the passage of a MCS, and flight 56, flown in the morning, in coordination with the BAE 146 aircraft, to study chemistry at the beginning of the day. The mean thermodynamic and dynamic conditions of the mixed layer measured during the flights are illustrated in Figures 7 and 8, giving the

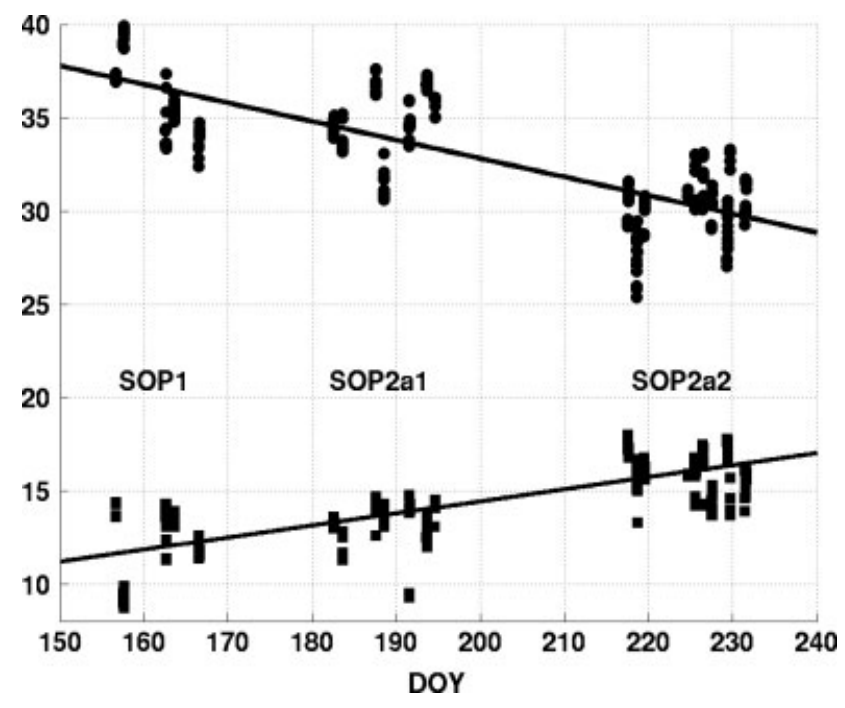

Figure 7. Potential temperature $(\bullet)\left({ }^{\circ} \mathrm{C}\right)$ and water vapour mixing ratio (घ) $\left(\mathrm{g} \mathrm{kg}^{-1}\right)$ averaged over all level legs flown within the ABL during the three SOPs. The solid lines are the linear fits through the data.
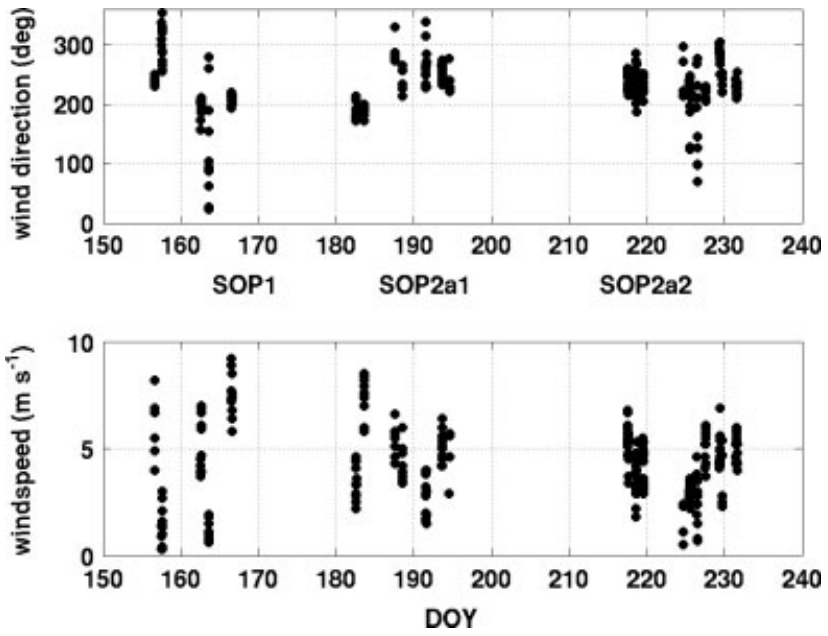

Figure 8. As Figure 7, but for wind speed and wind direction.

evolution related to the season. As expected, temperature and humidity show an opposite trend from dry and warm conditions to moister and colder conditions: a $0.1{ }^{\circ} \mathrm{C} \mathrm{day}^{-1}$ decrease for potential temperature and a $0.06 \mathrm{~g} \mathrm{~kg}^{-1} \mathrm{day}^{-1}$ increase for the water vapour mixing ratio. There is some variability in the data from one SOP to the other, which is linked to

(i) the scatter in the latitudes overflown,

(ii) the variability in the flight times (which was larger during SOP2a2),

(iii) the variability in the surface conditions in case of rainfall events during the preceding days or hours (e.g. flight 42 (DOY 218), a post-rainfall flight, shows a low temperature of $25^{\circ}$ ) and

(iv) the variability of the net radiation, especially during SOP2a2, due to some very cloudy days.

This variability is likely to be found in the turbulent parameters as well. 
The wind characteristics are shown in Figure 8. Wind was highly variable during the first SOP, both in speed and direction. It could blow from the west and from the east since this SOP took place during the transition period when the ITD was close to Niamey, i.e. when the wind could turn from the Harmattan to the monsoon during the day (Lothon et al., 2008). When the Harmattan was blowing (easterly or northerly direction), it was usually weak. When the monsoon was blowing, the ABL wind could be quite strong (up to $9 \mathrm{~m} \mathrm{~s}^{-1}$ ). Two flights of SOP1 (flights 18 on DOY 157 and 22 on DOY 163) experienced a shift from the monsoon to the Harmattan between the first vertical plane and the second. During SOP2a1 and SOP2a2, the wind was steadier, blowing from the southwest (monsoon) most of the time. It was seldom stronger than $7 \mathrm{~m} \mathrm{~s}^{-1}$ and sometimes very light. Flight 52 on DOY 226 occurred just before the passage of a MCS. The wind was still light and its direction was variable.

The flights performed during the three months of aircraft measurements show drastically different conditions of boundary-layer depths from one SOP to the next as shown in Figure 9, where the time evolution of $Z_{\mathrm{i}}$ during each flight has been assumed to be linear (Table I). SOP1 had larger $Z_{\mathrm{i}}$ and larger growth rates. A particularly sharp growth of the ABL $\left(495 \mathrm{~m} \mathrm{~h}^{-1}\right)$ was encountered for flight 18 (DOY 157). The proximity of the ITD (Canut et al., 2009) and its diurnal shift to the south made the wind turn from the monsoon to the Harmattan during this flight (Figure 8: the wind direction was 290-320 which is a transitional direction between the monsoon and the Harmattan). During that flight, the sharp temperature and humidity variation that usually caps the ABL vanished, so the ABL could grow freely into the SAL. During the onset period, the ITD location oscillated in the vicinity of Niamey. During flight 22 (DOY 163) the ABL also experienced a rotation of the wind and a large growth rate $\left(470 \mathrm{~m} \mathrm{~h}^{-1}\right)$. For flight 34 (DOY 191), for which first plane was flown just south of the ITD (the aircraft moved to the north), the ABL growth rate was $529 \mathrm{~m} \mathrm{~h}^{-1}$.

During the rainfall season, $Z_{\mathrm{i}}$ was smaller due to the presence of moister and cooler conditions, and to the consumption of available energy by evaporation instead of ABL heating (see next section). Morning and late afternoon flights also showed smaller $Z_{\mathrm{i}}$.

The relative values of $Z_{\mathrm{i}}$ and $Z_{\mathrm{s}}$ showed differences among the various SOPs (Table I). During the first two SOPs, $Z_{\mathrm{i}}$ reached $Z_{\mathrm{s}}$ most of the time and even exceeded $Z_{\mathrm{s}}$. Table $I$ indicates that $Z_{\mathrm{s}} / Z_{\mathrm{i}}$ was always lower than 1.2 , and often lower than 1 (except for flight 33 for which $Z_{\mathrm{i}}$ remained very small throughout the flight). Note that, when the wind turns from the monsoon to the Harmattan, $Z_{\mathrm{s}}$ is no longer defined.

After the onset, $Z_{\mathrm{i}}$ remained lower than $Z_{\mathrm{s}}: Z_{\mathrm{s}} / Z_{\mathrm{i}}$ was very often larger than 2 and could reach 3.5. Kalapureddy et al. (2009) made a statistical analysis of boundary-layer depths and monsoon depths, using the 2006 Niamey UHF observations. Comparing premonsoon to monsoon conditions, they indicate that $Z_{\mathrm{i}}$

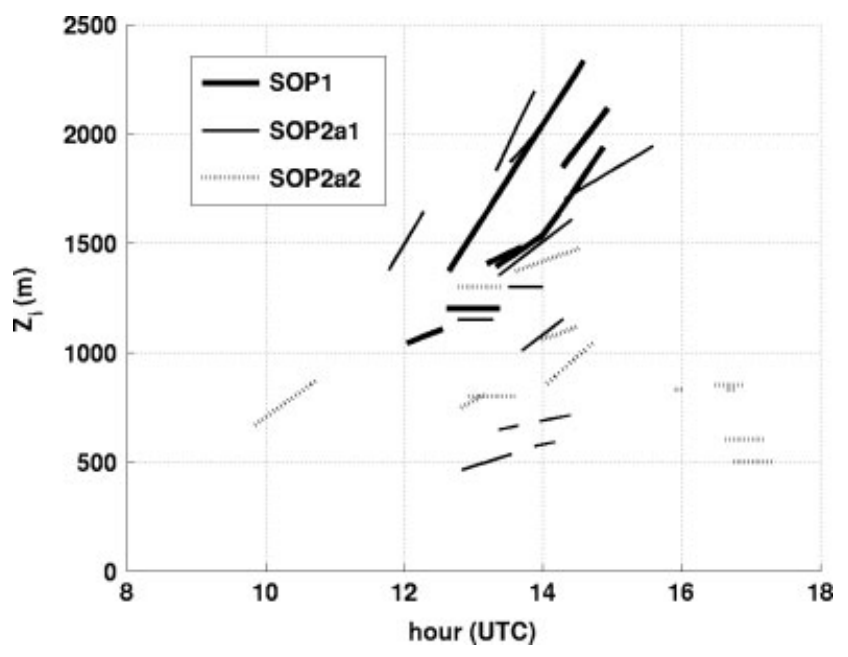

Figure 9. Evolution of the boundary-layer depths during the flights (see Table I).

increases during the day up to $2500 \mathrm{~m}$ on average before the monsoon onset, considerably above $Z_{\mathrm{s}}(1500 \mathrm{~m}$ on average) (their Figure 8). The opposite is observed during the monsoon period $\left(1000 \mathrm{~m}\right.$ and $1200 \mathrm{~m}$ for $Z_{\mathrm{i}}$ and $Z_{\mathrm{s}}$, respectively).

\section{Vertical flux profiles}

Heat and moisture fluxes $\left(\overline{w^{\prime} \theta^{\prime}}\right.$ and $\overline{w^{\prime} r_{\mathrm{v}}^{\prime}}$, respectively) were found to change linearly with height over the mixed layer, whatever the SOP (not shown). The $R^{2}$ linear regression coefficients of the covariances versus the reduced height were $0.95 \pm 0.06$ for $\overline{w^{\prime} \theta^{\prime}}$ and $0.77 \pm 0.20$ for $\overline{w^{\prime} r_{\mathrm{v}}^{\prime}}$. So surface fluxes could be deduced from a vertical extrapolation of the covariances measured along the stacked legs. Surface heat fluxes observed during the three periods are indicated in Table III and displayed in Figure 10(a) and (b) as a function of time. Again, two periods, before and after the onset, are distinguished. Surface sensible heat flux $H_{0}$ was higher and more scattered before the onset, with values varying between 50 and $200 \mathrm{~W} \mathrm{~m}^{-2}$, and could decrease to very small values, close to zero in SOP2a2, just after rainfall (flights 42, 50 and 57 in Table III) when the surface had not yet warmed and dried. In general, $H_{0}$ seldom exceeded $80 \mathrm{~W} \mathrm{~m}^{-2}$ during this SOP. Surface latent heat flux $L E_{0}$ started from small values during SOP1 (0 to $120 \mathrm{~W} \mathrm{~m}^{-2}$ ) and gradually increased in the monsoon setting. Its values varied considerably during SOP2a2, ranging from $30 \mathrm{~W} \mathrm{~m} \mathrm{~m}^{-2}$ (just after a rainfall event when the ABL had not yet recovered) to $450 \mathrm{~W} \mathrm{~m}^{-2}$. Consequently, the evaporative fraction, represented in Figure $10(\mathrm{c})$, rose from $0-0.5$ to $0.6-1$. This rise is even sharper than that found during HAPEX-Sahel for which a variation between 0.8 and 0.4 was reported between the monsoon and the post-monsoon periods, based on ground measurements (Gash et al., 1997) or aircraft measurements (Saïd et al., 1997). Note that, during AMMA, the values close to 1 occurred during the post-rainfall flights 42,50 and 57 . 


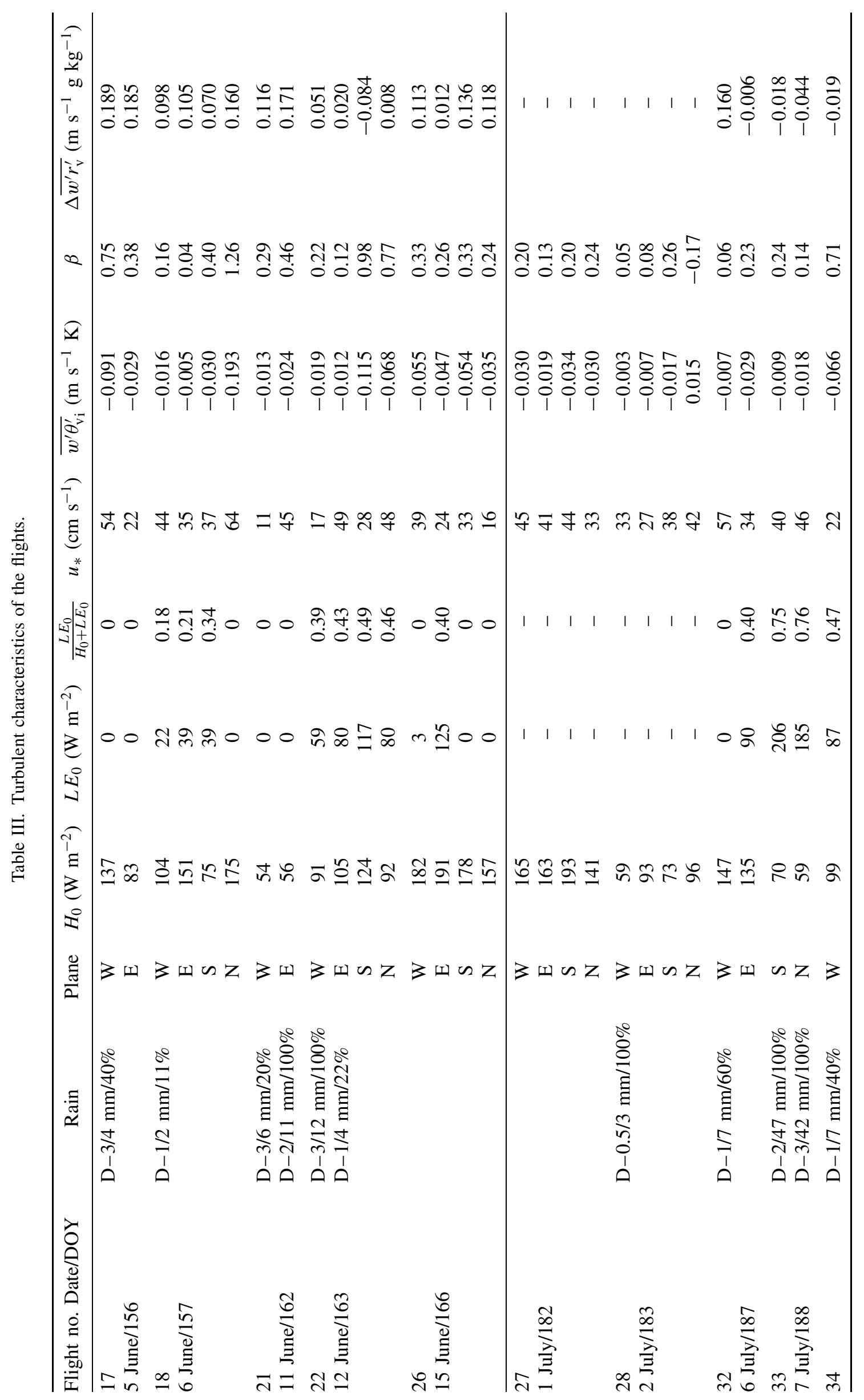




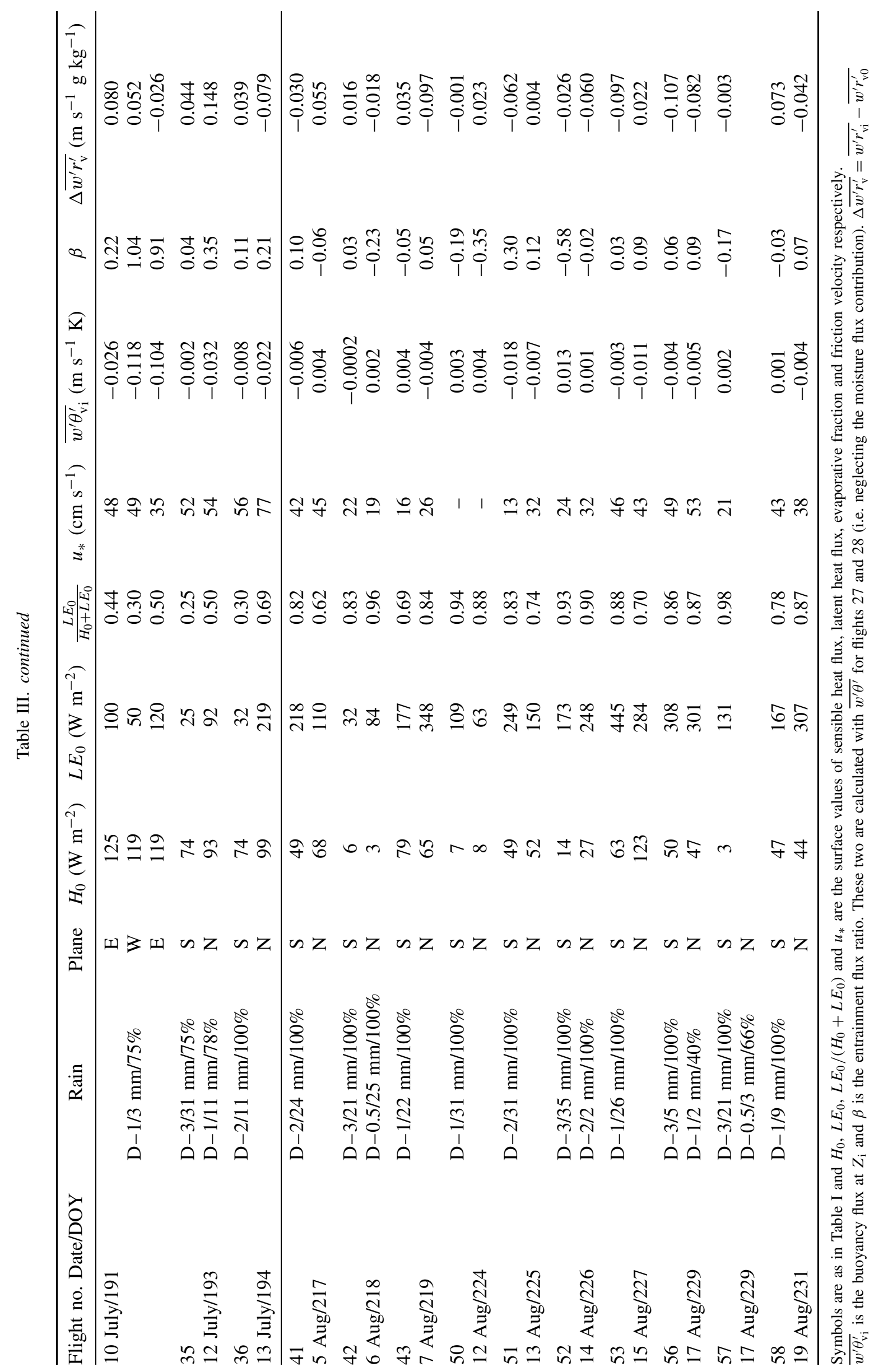


The sum of $H_{0}+L E_{0}$ also showed an increase from 100-320 to $50-500 \mathrm{~W} \mathrm{~m}^{-2}$ (Figure $10(\mathrm{~d})$ ). The large scatter in $L E_{0}$ found during the last SOP is a good reflection of the variability noted previously in the thermodynamic parameters since this variability partly vanishes when the moisture flux is normalized (Figure 10(c)).

Figure 11 displays heat, moisture and momentum fluxes versus the reduced height $Z_{*}$ and according to the SOP. Covariances are not normalized here so that the absolute values can be compared SOP by SOP. The normalized values are shown by Canut et al. (2009). $R^{2}$ linear regression coefficients for $\overline{w^{\prime} \theta^{\prime}}$ are $0.53,0.57$ and 0.47 for SOP1, SPO2a1 and SOP2a2 respectively (Figure 11(a)). These coefficients do not quantify the linearity of the individual profiles but the variability within the various flights, reflecting the variability in thermodynamics described above. The vertical profiles of the heat flux decrease with $Z_{*}$. They have steeper slopes and smaller surface values (noted previously) during SOP2a2, which implies lower heating rates $(\mathrm{d} \theta / \mathrm{d} t)$ and consequently lower growth rates of the boundary layer. This is in agreement with our previous result on boundary-layer heights. Heights and growth rates are smaller during the monsoon period.

The moisture flux (Figure 11(b)) behaved in two different ways according to the SOP. Entrainment flux could be very large before the monsoon onset (up to $0.17 \mathrm{~g} \mathrm{~kg}^{-1} \mathrm{~m} \mathrm{~s}^{-1}$ ) and surface covariances very small ( $R^{2}$ is 0.58 for $\mathrm{SOP} 1$ ). So an $L E_{0}$ close to zero due to the dryness of the surface does not mean that the moisture flux is equal to zero in the ABL. In contrast, the vertical profiles of moisture could have either a positive or negative slope during SOP2a and SOP2b, which explains the large scatter in the corresponding covariances indicated in Figure 11(b).

Large values of entrainment flux are due to the dryness of the overlying layer. In fact, even if the evaporation is zero at the surface, the boundary layer gains moisture during the night due to advection of the monsoon air by the nocturnal jet (Lothon et al., 2008). If the boundary layer is sufficiently energetic to incorporate some air from the SAL by entrainment, it generates drier, descending air parcels (also named dry tongues in Canut et al., 2009). Moeng and Wyngaard (1984) decompose the scalar mixing ratio field into a top-down field and a bottom-up field, driven by either the entrainment flux or the surface flux. They show that the turbulence statistics (such as vertical distribution of variance, covariance, energy budget) associated with the two fields are quite different. During the AMMA SOP1, moisture covariances at the inversion are large, whereas surface moisture fluxes are small, so top-down diffusion prevails. Evaporation occurs in SOP2a2 and the vertical profiles of moisture flux can either decay with increasing height (bottom-up diffusion prevails) or increase. Under these conditions, both topdown transfers and bottom-up transfers are present.

These two processes are well captured by the evolution of $\overline{w^{\prime} \theta_{\mathrm{vi}}^{\prime}}$ (buoyancy flux at the top of the ABL; $\theta_{\mathrm{v}}$ is the virtual temperature) (Figure 10(e) and Table III) and entrainment flux ratio $\beta$ (Figure 10(f) and Table III), defined as:

$$
\beta=-\frac{\overline{w^{\prime} \theta_{\mathrm{vi}}^{\prime}}}{\overline{w^{\prime} \theta_{\mathrm{v} 0}^{\prime}}} .
$$

Over the entire set of estimates, $\beta=0.21 \pm 0.34$, which is close to 0.2 , the usual value reported in the literature. However the results are significantly different for the three SOPs. Large negative buoyancy fluxes at $Z_{\mathrm{i}}$ and large $\beta$ (around 0.5 ) are found during SOP1 and confirm the results shown in Figure 11(b). Top-down processes dominate. Small buoyancy fluxes at $Z_{\mathrm{i}}$ and $\beta$ close to 0 during SOP2a2 indicate a mix of bottom-up and topdown processes. SOP2al shows intermediate conditions. Note that positive values of buoyancy flux (and negative values of $\beta$ ) are also encountered during SOP2a 2 when the heat flux is negligible and the moisture flux large. The variation with height of the moisture flux is indicated in last column of Table III) in terms of $\overline{w^{\prime} r_{\mathrm{vi}}^{\prime}}-\overline{w^{\prime} r_{\mathrm{v} 0}^{\prime}}$.

Another important feature of this dataset is the variability in momentum flux within the whole depth of the boundary layer (Figure 11(c)). This has been plotted versus the reduced height in terms of local friction velocity defined as:

$$
u_{* l}=\left({\overline{w^{\prime} u^{\prime}}}^{2}+{\overline{w^{\prime} v^{\prime}}}^{2}\right)^{1 / 4} .
$$

This velocity is expected to decrease rapidly from the surface layer to a few hundred metres, and increase again close to $Z_{\mathrm{i}}$ due to the wind rotation. Such is not the case here, where it is variable and can be significant throughout the ABL (due to the frequent low wind values). It can reach $70 \mathrm{~cm} \mathrm{~s}^{-1}$ during the first SOP. Of course, the random error associated with this local friction velocity (not shown) is large and ranges between $50 \%$ and $150 \%$, with the largest values occuring during SOP1. This was to be expected since the momentum flux is the most difficult flux to measure (Lenschow and Stankov, 1986; Lambert and Durand, 1998). The highest values of local friction velocity are those of SOP1, between $0.3 Z_{\mathrm{i}}$ and $Z_{\mathrm{i}}$. This is not surprising since the wind was stronger during this period and also because $Z_{\mathrm{i}}$ remained close to $Z_{\mathrm{s}}$. Shear is generated by the wind rotation, which occurs at the top of the ABL. However, even if the ABL depth remains far smaller than the monsoon depth as during SOP2a2, there is always a significant shear within the ABL.

\section{Length-scales}

The wavelength $\lambda_{w}$ of the $w$ spectrum peak is presented in Figure 12(a). $\lambda_{w}$ is normalized by $Z_{\mathrm{i}}$ and plotted versus the reduced height. Each SOP is distinguished and average curves are plotted, using a second-order polynomial fit. $\lambda_{w} / Z_{\mathrm{i}}$ shows a maximum in the middle of the ABL and decreases sharply close to $Z_{\mathrm{i}}$ and to the surface (Caughey and Palmer, 1979; Bernard-Trottolo et al., 2003). Two parametrizations, proposed by Kaimal et al. (1976) and Caughey and Palmer (1979) are displayed in Figure 12(a) and expressed in Table IV. The 

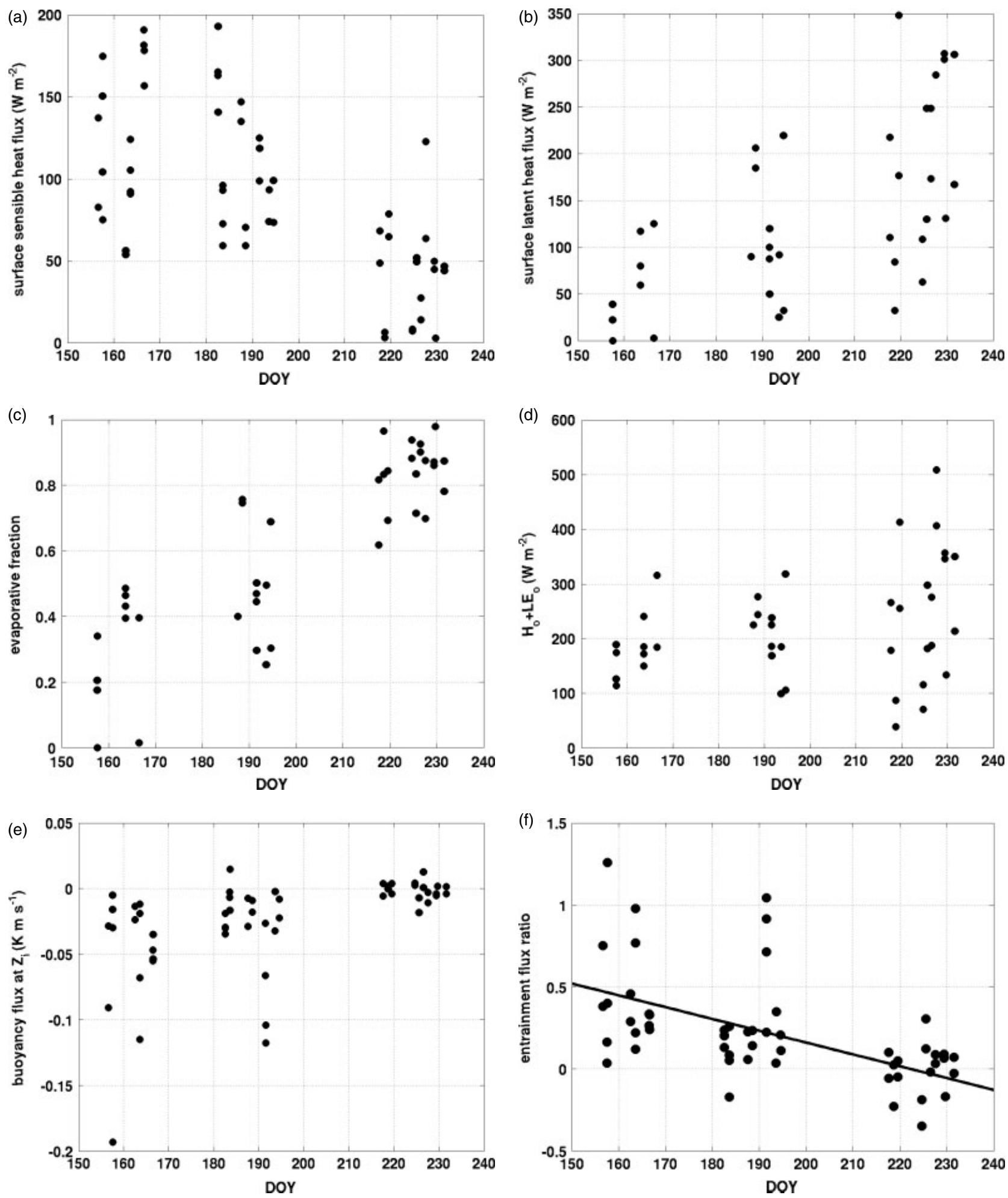

Figure 10. (a) Surface sensible heat flux, (b) surface latent heat flux, (c) evaporative fraction, (d) sum of the surface sensible heat and latent heat fluxes, (e) buoyancy flux at $Z_{i}$, and (f) entrainment flux ratio, all as a function of time.

latter fits the AMMA data better since it retrieves the sharp decrease near the interfaces. If we consider that $\lambda_{w}$ represents the size of the largest eddies, it is likely that $\lambda_{w}$ has to decrease near the two interfaces. However, the decrease observed during AMMA is enhanced by the large value of the maximum at $0.5 Z_{\mathrm{i}}$, especially during SOP1. $\lambda_{w} / Z_{\mathrm{i}}$ and $\lambda_{w}$ are compared in Table $\mathrm{V}$ for the three SOPs at two heights. At $0.5 Z_{\mathrm{i}}, \lambda_{w}$ is 1.7 times the boundary-layer depth during SOP1 (i.e. $2.5 \mathrm{~km}$ on average with large scatter). It decreases close to $Z_{\mathrm{i}}$ and to the surface. The maximum $\lambda_{w} / Z_{\mathrm{i}}$ is 1.4 during SOP2a1 $(1.8 \mathrm{~km})$ and $1.2(1.1 \mathrm{~km})$ during SOP $2 \mathrm{a} 2$ at $0.5 Z_{\mathrm{i}}$. If we assume $\lambda_{w}$ to be the size of the largest turbulent eddies 

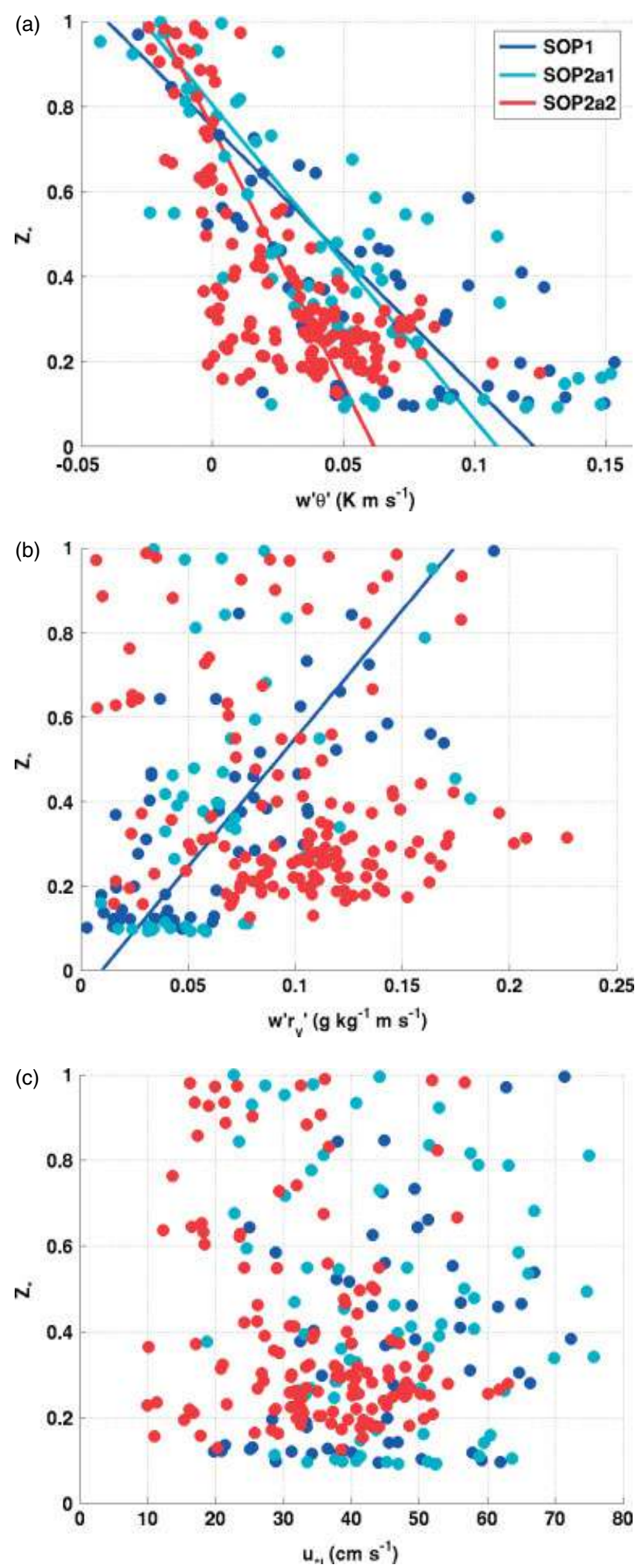

Figure 11. Vertical profiles of (a) heat flux, (b) moisture flux, and (c) local friction velocity. Regression lines are drawn, when significant, for each SOP.

that develop in the ABL, there is a significant difference in the eddy sizes between the SOPs. The difference is enhanced by the fact that the ABLs are deeper during the first SOP, but Figure 12(a) proves that the difference remains for normalized $\lambda_{w}$. The size of the largest eddies may have something to do with the characteristics of the dry tongues. At this stage of the study, we are not able to know whether these dry tongues are associated with mesoscale organization existing within the ABL. Lothon et al. (2007), who compared observations of the clear air ABL during HAPEX-Sahel on 8 October 1992 (during the drying period after the monsoon) to the results of a LES, showed evidence of organized structures with characteristic wavelengths of $2-3 \mathrm{~km}$ at $0.4 Z_{\mathrm{i}}$. They also related them to dry tongues penetrating into the $\mathrm{ABL}$.

The integral scale of vertical velocity (Figure 12(b)) and the flux integral scales (Figure 12(c) and (d)) show a similar vertical profile to $\lambda_{w}$ but the discrepancy between the SOPs at $0.5 Z_{\mathrm{i}}$ is no longer present. All show the same increase in the middle of the ABL and a sharp decrease at the ABL top for SOP1. The profiles suggested by Lenschow and Stankov (1986) (Figure 12(b), (c) and (d) and Table IV) do not fit our dataset very well, especially for $l_{w r_{\mathrm{v}}} / Z_{\mathrm{i}}$ close to the surface. The length-scales measured during AMMA are usually larger. A similar result was reported by Lothon et al. (2007). This could be due to the large variability in surface moisture during AMMA. Furthermore, the $1 / 2$ power-law suggested by Lenschow and Stankov (1986) does not retrieve the curvature obtained with a polynomial fit for the AMMA data. An alternative could have been to use two exponential functions as in Caughey and Palmer (1979).

The difference encountered between $\lambda_{w}$ and $l_{w}$ shows that the increase of $\lambda_{w}$ is essentially linked to meso- or sub-meso-scale processes. We also found that $l_{w}, l_{w \theta}$ and $l_{w r_{\mathrm{v}}}$ profiles differed from one SOP to the other when they were not normalized. Integral scales were always larger during SOP1 (deeper ABLs). This is part of the difference observed in the random error of the moisture flux between SOP1 and SOP2a2.

\section{Correlation coefficients}

Heat and moisture flux correlation coefficients, $R_{w \theta}$ and $R_{w r_{\mathrm{v}}}$, are shown in Figure 13. The profiles are like those commonly reported in the literature for $r_{w \theta}$ with a decrease from 0.7 at the surface to -0.2 at $Z_{\mathrm{i}}$, negative values accounting for entrainment. Alternatively, $r_{w r_{\mathrm{v}}}$ profiles display either a positive or negative slope, in relation to the slope of the moisture flux during SOP1 (positive slope) and SOP2a2 (negative slope). The larger the flux, the larger the correlation coefficient. Note, however, that $R_{w r_{\mathrm{v}}}$ never exceeds 0.3 during SOP1, so the very large values of moisture flux reported in section 7 are due to large variances of $\mathrm{w}$ and $r_{\mathrm{v}}$. Lohou et al. (2009), who analysed the seasonal variation of the $r_{\mathrm{v}}$ variance at ground level during the whole of 2006, found large $r_{\mathrm{v}}$ variances whatever the season. The site they studied was located $800 \mathrm{~km}$ to the south of Niamey, i.e. in an area with more vegetation. Nevertheless, they showed that, during the driest period, these large $r_{\mathrm{v}}$ variances were linked to top-down transfers of dryness.

During SOP2a2, $R_{w r_{\mathrm{v}}}$ at the surface reached 0.5 as in ABLs where the surface evaporation dominates. Our 

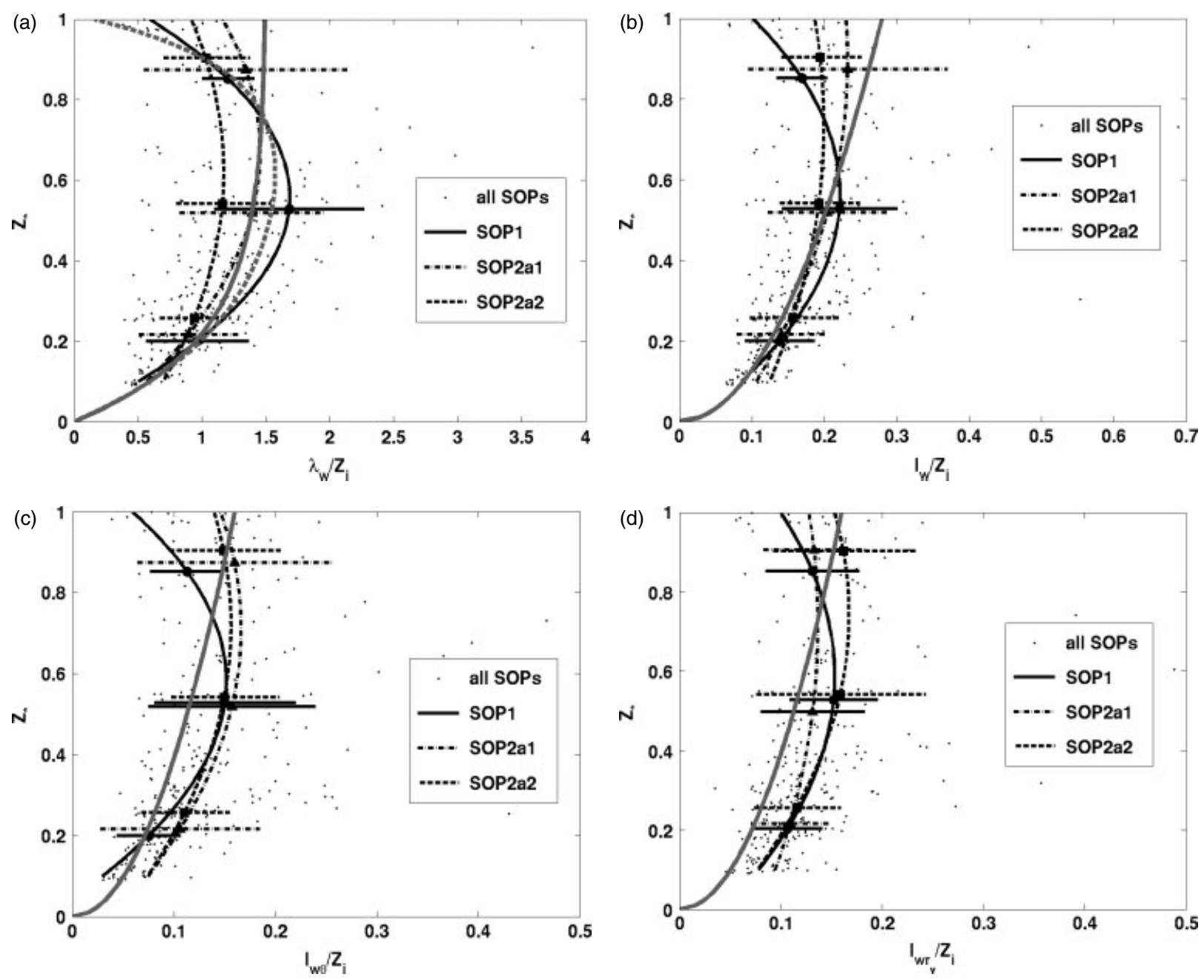

Figure 12. Vertical profiles of normalised (a) $\lambda_{w}$, (b) $l_{w}$, (c) $l_{w \theta}$ and (d) $l_{w r_{\mathrm{v}}}$. Averages, standard deviations (horizontal lines) and second-order polynomial regressions (black lines) are drawn for each SOP. In (a), the grey lines are the relations suggested by Kaimal et al. (1976) (solid) or Caughey and Palmer (1979) (dashed). In (b), (c) and (d) the grey lines are the relations suggested by Lenschow and Stankov (1986).

Table IV. Parametrizations suggested by previous authors for turbulent length-scales.

Kaimal et al. (1976)

Caughey and Palmer (1979)

Lenschow and Stankov (1986)

$$
\begin{gathered}
\frac{\lambda_{w}}{Z_{\mathrm{i}}}=1.5\left\{1-\exp \left(\frac{-5 Z}{Z_{\mathrm{i}}}\right)\right\} \\
\frac{\lambda_{w}}{Z_{\mathrm{i}}}=1.8\left\{1-\exp \left(\frac{-4 Z}{Z_{\mathrm{i}}}\right)-0.0003 \exp \left(\frac{8 Z}{Z_{\mathrm{i}}}\right)\right\} \\
\frac{l_{w}}{Z_{\mathrm{i}}}=0.28\left(\frac{Z}{Z_{\mathrm{i}}}\right)^{1 / 2} ; \frac{l_{w x}}{Z_{\mathrm{i}}}=0.16\left(\frac{Z}{Z_{\mathrm{i}}}\right)^{1 / 2}
\end{gathered}
$$

Table V. Averages and standard deviations of $\lambda_{w}$ for the three SOPs.

\begin{tabular}{lccc}
\hline & SOP1 & SOP2a1 & SOP2a2 \\
\hline$Z=0.9 Z_{\mathrm{i}}$ & & & \\
$\lambda_{w} / Z_{\mathrm{i}}$ & $1.20 \pm 0.20$ & $1.34 \pm 0.80$ & $1.03 \pm 0.34$ \\
$\lambda_{w}(\mathrm{~m})$ & $1475 \pm 397$ & $1363 \pm 614$ & $821 \pm 383$ \\
$Z=0.5 Z_{\mathrm{i}}$ & & & \\
$\lambda_{w} / Z_{\mathrm{i}}$ & $1.68 \pm 0.59$ & $1.39 \pm 0.57$ & $1.16 \pm 0.38$ \\
$\lambda_{w}(\mathrm{~m})$ & $2531 \pm 945$ & $1800 \pm 569$ & $1090 \pm 441$ \\
\hline
\end{tabular}

results for $R_{w r_{\mathrm{v}}}$ do not confirm the correlation coefficients obtained from the LES model used by Moeng and
Wyngaard (1984). Their profile peaks at the middle of the ABL, with a decrease at the interfaces, and is the same for bottom-up or top-down processes. This means that the singularity of the covariance profiles that they point out, according to the direction of the dominant transport, is totally linked to the $w$ and $r_{\mathrm{v}}$ variance profiles. In situ measurements seem to refute this result. Mann and Lenschow (1994) suggest for example that $R_{w s}$ profiles vary with $\gamma=F_{Z_{\mathrm{i}}} / F_{0}$, the ratio of the fluxes at the two interfaces. Their profiles decrease with increasing height when $\gamma$ is in the range $[-1,-0.2]$. This is the case for $R_{w \theta}$ and agrees with our linear relationship in Figure 13(a). Their profiles remain constant in the ABL and then decrease at $Z_{i}$ when $\gamma$ is in the range $[0,1]$. 

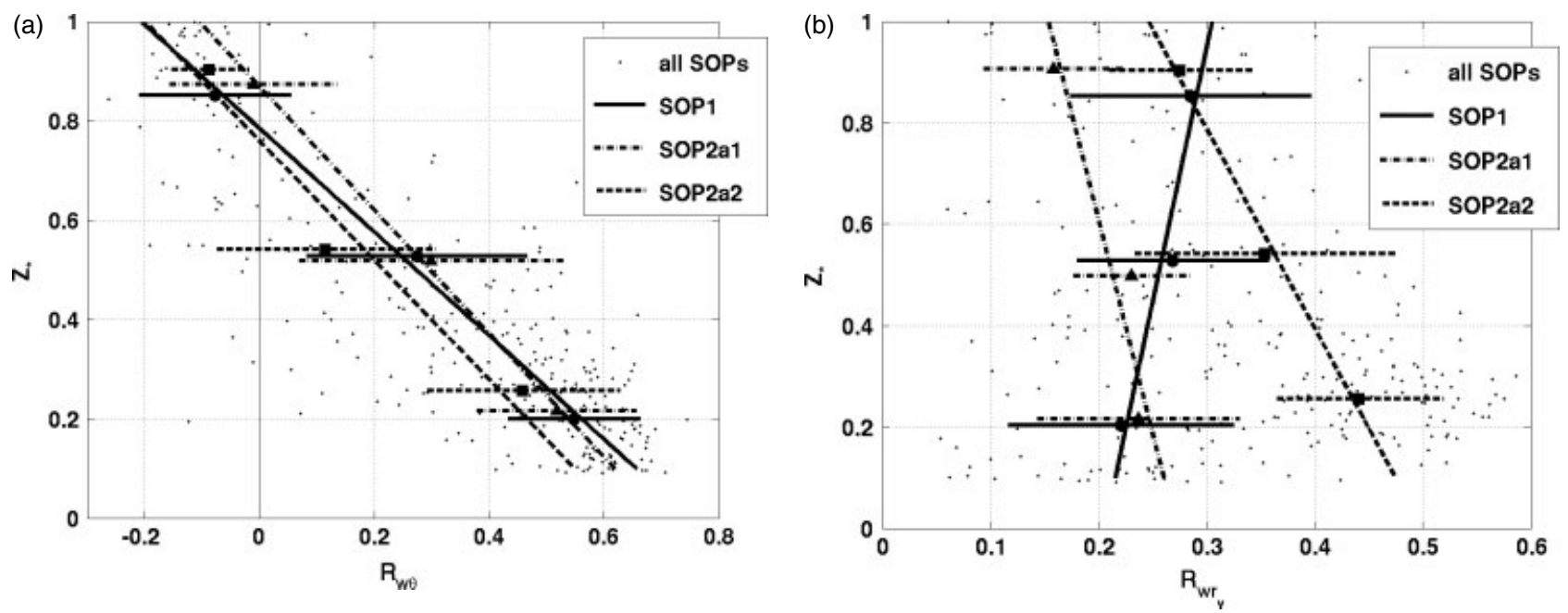

Figure 13. Vertical profiles of (a) heat and (b) moisture flux correlation coefficients. Averages, standard deviations (horizontal bars) and linear regression lines (when significant) are plotted.

This is the case for the moisture flux during SOP2a2 (Figure 13(b)). The special case of SOP1, when $\gamma$ for moisture is larger than 1 , is not considered in Mann and Lenschow (1994). In fact, it is reasonable to imagine that $\mathrm{w}$ and $r_{\mathrm{v}}$ are better correlated near the scalar source (moisture at the ground, dryness at $Z_{\mathrm{i}}$ ).

We find correlation coefficients for momentum that are always smaller than 0.3 , as usually obtained in convective ABLs (not shown here). They do not display any relationship with height or with time.

Profiles of correlation coefficients (Figure 13(a) and (b)) help to explain the vertical variation of the random errors, using Equation (2). Note that the sample length, $L$, does not vary much and contributes only $6 \%$ to the $\epsilon_{\mathrm{r}}$ variability. If we compute $\mathrm{d} \epsilon_{\mathrm{r}} / \epsilon_{\mathrm{r}}$, the relative error of the random error in terms of $\mathrm{d} l_{w s} / l_{w s}$ and $\mathrm{d} R_{w s} / R_{w s}$, we find that the contribution of the correlation coefficient is twice that of the length-scale. Accordingly, the moisture flux error $\epsilon_{\mathrm{r}}$ increases with height from 19 to $40 \%$ during SOP2a2, simultaneously with the decrease in magnitude of the correlation coefficient. This is usual for a mixed bottom-up/top-down process (Bernard-Trottolo et al., 2003). Due to the lower correlation coefficients, $\epsilon_{\mathrm{r}}$ is much larger for SOP1 and SOP2a1, and varies from around $45-60 \%$ to $40-70 \%$.

\section{Concluding remarks}

The seasonal evolution of the Sahelian boundary layer has been studied from pre-monsoon to mature monsoon conditions, using repetitive flights describing the monsoon layer as well as the low Saharan layer. Surface heat fluxes were found to increase whereas moisture fluxes decreased. Before the monsoon onset, the ABLs frequently grew higher than the monsoon-Harmattan interface, which generated shear at the ABL top. After the onset, ABLs were not so deep.

The main issue associated with the behaviour of the Sahelian boundary layer from pre-onset to post-onset monsoon conditions is the important role played by the location of the moisture source in the boundary layer: dryness at the top of the ABL before the onset, and a mixture of dryness at the top of the ABL and moisture at the surface after the onset. This is linked to the progressive moistening of the surface over the period, to the entrainment intensity at the top of the ABL and to the location of the ABL top relative to the shearing layer separating the monsoon flow from the Harmattan flow. During the driest period, the $\mathrm{ABL}$ and the Harmattan layer interact and the shear between the two increases the entrainment. During the wet period, a cloud layer separates the ABL and the Harmattan layer. Future study of the impact of these boundary-layer processes on the surface processes, and on the relative contribution of the clouds and the surface after the onset would be well worthwhile. We also show that the errors associated with the flux calculation are not larger than in midlatitude boundary layers and are closely linked to the period of measurements with larger errors before the onset. We will study this point further, considering that the surface energy budget is probably not balanced with small $H_{0}+L E_{0}$ as found during SOP1 (Figure 10(d): the largest value is $320 \mathrm{~W}^{-2}$ ). This lends support to the findings of Huang et al. (2008) who investigated the impact of a scalar source location on the flux imbalance by implementing a top-down and a bottom-up tracer in a large-eddy simulation model. They found that the flux imbalance was dominated by either bottom-up diffusion or entrainment according to the location of the tracer source. Kanda et al. (2004) and Lothon et al. (2007) also concluded that the existence of turbulent organized structures was responsible for a flux imbalance and there are some hints of the presence of such structures for some AMMA flights.

\section{Acknowledgements}

The authors of this work are funded by INSU-CNRS and Toulouse University. Based on a French initiative, 
AMMA was built by an international scientific group and is currently funded by a large number of agencies, especially from France, UK, USA and Africa. It has been the beneficiary of a major financial contribution from the European Community's Sixth Framework Research Programme. Detailed information on scientific coordination and funding is available on the AMMA International web site http://www.amma-international.org. The TRMM data used in this study were acquired using the GES-DISC Interactive Online Visualization ANd aNalysis Infrastructure (Giovanni) which is part of NASA's Goddard Earth Sciences (GES) Data and Information Services Center (DISC), which we also thank. We would like to express special thanks to the SAFIRE team who operated the ATR aircraft and provided measurements. We are most grateful to them for providing us with a fully operating aircraft after several years of very hard and stressful work. We also thank the TRAMM team from CNRM (Centre National de la Recherche Météorologique) at Météo-France for their help in computing the data.

\section{References}

Ancellet G, Leclair de Bellevue J, Mari C, Nedelec P, Kukui A, Borbon A, Perros P. 2009. Effects of regional-scale and convective transports on tropospheric ozone chemistry revealed by aircraft observations during the wet season of the AMMA campaign. Chem. Phys. 9: 383-411.

Bernard-Trottolo S, Campistron B, Druilhet A, Lohou F, Saïd F. 2003. TRAC98: Detection of coherent structures in a convective boundary layer using airborne measurements. Boundary-Layer Meteorol. 111: $181-224$.

Brown EN, Friehe CA, Lenschow DH. 1983. The use of pressure fluctuations on the nose of an aircraft for measuring air motion. J. Climatol. Appl. Meteorol. 22: 171-180.

Canut G, Lothon M, Saïd F. 2009. Observation of entrainment at the interface between monsoon flow and Saharan air layer. $Q . J . R$. Meteorol. Soc. 136(s1): 34-46.

Caughey SJ, Palmer SG. 1979. Some aspects of turbulence structure through the depth of the convective boundary layer. $Q$. J. $R$. Meteorol. Soc. 105: 811-827.

Crumeyrolle S, Gomes L, Tulet P, Matsuki A, Schwarzenboeck A, Crahan K. 2008. Increase of the aerosol hygroscopicity by aqueous mixing in a mesoscale convective system: A case study from the AMMA campaign. Atmos. Chem. Phys. 8: 6907-6924.

Durand P, Bourcy T. 2001. Observations of the turbulence structure within two stratcumulus-topped, marine boundary layers. BoundaryLayer Meteorol. 99: 105-125.

Durand P, Dupuis H, Lambert D, Bénech B, Druilhet A, Katsaros K, Taylor P, Weill A. 1998. Comparison of sea surface flux measured by instrumented aircraft and ship during SOFIA and SEMAPHORE experiments. J. Geophys. Res. 103: 25125-25136.

Flamant C, Knippertz P, Parker D, Chaboureau J-P, Lavaysse C, Agusti-Panareda A, Kergoat L. 2009. The impact of a mesoscale system cold pool on the northern propagation of the intertropical discontinuity over West Africa. Q. J. R. Meteorol. Soc. in press.

Gash J, Kabat P, Monteny B, Amadou M, Bessemoulin P, Billing H, Blyth E, deBruin H, Elbers J, Friborg T, Harrison G, Holvill C, Lloyd C, Lhomme J, Moncrieff J, Puech D, Sogaard H, Taupin J, Tuzet A, Verhoef A. 1997. The variability of evaporation during the HAPEX-Sahel Intensive Observation Period. J. Hydrol. 188-189: 385-399.

Goutorbe J-P, Lebel T, Tinga A, Bessemoulin P, Brouwer J, Dolman A, Engmam E, Gash J, Hoepffner M, Kabat P, Kerr Y, Monteny B, Prince S, Saïd F, Sellers P, Wallace J. 1994. HAPEX-Sahel: Largescale study of land-atmosphere interactions in the semi-arid Tropics. Ann. Geophys. 12: 53-64.

Hildebrand PH. 1991. Errors in eddy correlation turbulence measurements from aircraft: Application to HAPEX-MOBILHY. In Land-surface evaporation: Measurement and parametrization, Schmugge TJ, André JC. (eds.) Springer-Verlag: New York.
Huang J, Xuhui L, Patton E. 2008. A modelling study of flux imbalance and the influence of entrainment in the convective boundary layer. Boundary-Layer Meteorol. 127: 273-292.

Janicot S, Thorncroft C, Ali A, Asencio N, Berry G, Bock O, Bourles B, Caniaux G, Chauvin F, Deme A, Kergoat L, Lafore JP, Lavaysse C, Lebel T, Marticorena B, Mounier F, Nedelec P, Redelsperger J-L, Ravegnani F, Reeves C, Roca R, de Rosnay P, Sclager H, Sultan B, Tomasini M, Ulanovsky A. 2008. Large-scale overview of the summer monsoon over West Africa during the AMMA field experiment in 2006. Ann. Geophys. 26: 2569-2595.

Kaimal JC, Wyngaard JC, Haugen DA, Coté OR, Izumi Y, Caughey SJ, Readings CJ. 1976. Turbulence structure in the convective boundary layer. J. Atmos. Sci. 33: 2152-2169.

Kalapureddy M, Lothon M, Lohou F, Saïd F, Campistron B. 2009. Wind profiler observations of the intra-seasonal variability of the West African monsoon troposphere dynamics. Q. J. R. Meteorol. Soc. 136(s1): 77-91.

Kanda M, Inagaki A, Letzel MO, Raasch S, Watanabe T. 2004. LES study of the energy imbalance problem with eddy covariance fluxes. Boundary-Layer Meteorol. 110: 381-404.

Lambert D, Durand P. 1998. Aircraft-to-aircraft intercomparison during SEMAPHORE. J. Geophys. Res. 103: 25109-25123.

Lambert D, Durand P. 1999. The marine atmospheric boundary layer during SEMAPHORE. I: Mean vertical structure and non-axis symmetry of turbulence. Q. J. R. Meteorol. Soc. 125: 1359-1381.

Lebel T, Parker DJ, Flamant C, Bourles B, Marticorena B, Mougin E, Peugeot C, Gaye A, Haywood J, NGamini J-B, Polcher J, Redelsperger J-L, Thorncroft C. 2009. The AMMA field campaigns: Multiscale and multidisciplinary observations in the West African region $Q$. J. R. Meteorol. Soc. 136(s1): 8-33.

Lenschow DH. 1986. Aircraft measurements in the boundary layer. Pp 39-56 in Probing the Atmospheric Boundary Layer, Lenschow DH. (ed.) Amer. Meteorol. Soc: Boston, USA.

Lenschow DH, Stankov BB. 1986. Length scales in the convective boundary layer. J. Atmos. Sci. 43: 1198-1209.

Lloyd C, Bessemoulin P, Cropley F, Gulf A, Dolman A, Elbers J, Heusinkveld B, Moncrieff J, Monteny B, Verhoef A. 1997. A comparison of surface fluxes at the HAPEX-Sahel fallow bush sites. J. Hydrol. 188-189: 400-425.

Lohou F, Saïd F, Lothon M, Durand P, Serca D. 2009. Humidity turbulent scale at the surface in relation with boundary-layer processes: AMMA experiment. Boundary-Layer Meteorol. 136(s1): $107-124$.

Lothon M, Couvreux F, Donier S, Guichard F, Lacarrère P, Noilhan J, Saïd F. 2007. Impact of the coherent eddies on airborne measurements of vertical turbulent fluxes. Boundary-Layer Meteorol. 124: 425-447.

Lothon M, Saï F, Lohou F, Campistron B. 2008. Observation of the diurnal cycle in the low troposphere of West Africa. Mon. Weather Rev. 136: 3477-3500.

Mann J, Lenschow DH. 1994. Errors in airborne flux measurements. J. Geophys. Res. 99: 14519-14526.

Messager C, Parker DJ, Reitebuch O, Agusti-Panareda A, Taylor C, Cuesta J. 2009. Structure and dynamics of the Saharan atmospheric boundary layer during the West African monsoon 2006 onset: Observations and analyses. Q. J. R. Meteorol. Soc. 136(s1): $107-124$.

Moeng CH, Wyngaard J. 1984. Statistics of conservative scalars in the convective boundary layer. J. Atmos. Sci. 41: 3161-3169.

Monteith J. 1991. Weather and Water in the Sudano-Sahelian zone. Soil water balance in the Sudano-Sahelian zone. Institute of Hydrology, IAHS Press: Wallingford, UK.

Redelsperger J, Thorncroft C, Diedhiou A, Lebel T, Parker DJ, Polcher J. 2006. African Monsoon Multidisciplinary Analysis (AMMA): An international research project and field campaign. Bull. Amer. Meteorol. Soc. 87: 1739-1746.

Saïd F, Attié JL, Bénech B, Druilhet A, Durand P, Marciniak MH, Monteny B. 1997. Spatial variability in airborne surface flux measurements during HAPEX-Sahel. J. Hydrol. 188-189: 878-911.

Saïd F, Corsmeier U, Kahltoff N, Kottmeier C, Lothon M, Wieser A, Hofherr T, Perros P. 2005. ESCOMPTE experiment: Intercomparison of four aircraft dynamical, thermodynamical, radiative and chemical measurements. Atmos. Res. 74: 217-252.

Stewart DJ, Taylor C, Reeves C, McQuaid J. 2008. Biogenic nitrogen oxide emissions from soils: Impact on $\mathrm{NOx}$ and ozone over West Africa during AMMA (African Monsoon Multidisciplinary Analysis) observational study. Atmos. Chem. Phys. 8: 2285-2297. 
Sullivan P, Moeng CH, Stevens B, Lenschow D, Mayor S. 1998. Structure of the entrainment zone capping the convective atmospheric boundary layer. J. Atmos. Sci. 55: 3042-3064.

Sultan B, Janicot S. 2003. The West African monsoon dynamics. Part II: The 'preonset' and 'onset' of the summer monsoon. J. Climate 16: $3407-3427$.

Taylor CM, Parker D, Harris P. 2007. An observational case study of mesoscale atmospheric circulations induced by soil moisture. Geophys. Res. Lett. 34: L15801, DOI: 10.1029/2007GL030572.
Wai MMK, Smith EA, Bessemoulin P, Culf AD, Dolman AJ, Lebel T. 1997. Variability in boundary-layer structure during HAPEX-Sahel wet-dry season transition. J. Hydrol. 188-189: 965-997.

Wyngaard JC. 1983. Boundary-layer modelling. Pp 69-106 in Atmospheric turbulence and Air Pollution Modelling, Nieuwstadt FTM, Van Dop H. (eds.) D. Reidel: Dordrecht, Boston. 